The Socialization of Performance Goals 


\begin{abstract}
How are competitive goals transmitted over time? As most competence-relevant contexts (e.g., school) are hierarchy-relevant (e.g., teacher/students), supervisors' performance-approach goals (desire to outperform others) should play a major role. We formulated a performance goals socialization hypothesis: The higher a supervisor's performance-approach goals, the stronger the effects of time on followers' performanceapproach and -avoidance (desire not to be outperformed by others) goals. Study 1, involving coaches and their soccer players, showed that indeed a performance goals socialization phenomenon exists. Study 2, involving thesis supervisors and their Ph.D. students, showed its consequences: performance goals socialization reduced subordinates' motivation and wellbeing over time. Study 3, involving video game team leaders and their players, showed its enabling condition: the stronger the subordinates' identification to their team, the more pronounced the performance goals socialization. Study 4, involving schoolteachers and their pupils, showed its directional moderator: the higher the subordinates' perceived selfcompetence, the higher the change in performance-approach goals over time, and the lower that in performance-avoidance goals. It is then crucial to consider social hierarchy when studying goal formation.
\end{abstract}

Keywords: Performance goals, leadership, socialization, social identification, selfcompetence. 


\section{The Socialization of Performance Goals}

\section{Introduction}

Asserting one's competence relative to others is one of the most deeply rooted goals in the Western world. From university laboratories (Hirsh, 2005) to sports fields (Grehaigne, Godbout, \& Bouthier, 1997), performance-approach goals are culturally promoted (Kasser, Cohn, Kanner, \& Ryan, 2007). Yet, these goals also have some social costs, as they have been linked to academic dishonesty (Murdock \& Anderman, 2006) or moral disengagement in sporting activity (Kavussanu, 2006). We are then left to wonder how performance goals could be reproduced. We argue that group supervisors are agents of goals socialization in achievement settings: The more supervisors pursue performance-approach goals, the more their subordinates will develop performance-based goals over time. In this article, we use the general terms supervisor (the agent of socialization) and subordinate (the target of socialization) to encompass various forms of hierarchical relations in educational (here, an amateur sports club, a university, and a school) and non-educational (a video-game tournament) settings.

\subsection{The Performance Goals Socialization Phenomenon}

Achievement goals are social-cognitive mental frames that guide individuals in interpreting, processing, and coping with competence-relevant situations (Kaplan \& Flum, 2010). The first generation of achievement goals research distinguished mastery goals (the orientation toward the acquisition of competences) from performance goals (the orientation toward the demonstration of competences; Dweck 1986), whereas the second generation differentiated performance-approach goals (the desire to outperform others) from performance-avoidance goals (the desire not to be outperformed by others; Elliot, 1999). ${ }^{1}$

Past research mostly focused on subordinates, be they pupils, employees, or athletes (see Elliot, McGregor, \& Gable, 1999; Van Yperen, 2003; Halvari \& Kjørmo, 1999, 
respectively). It was shown that subordinates' achievement goals are both stable traits (Elliot \& Thrash, 2002) and transient states (e.g., as shaped by perceptions of learning environment, Anderman \& Anderman, 1999). Hence, it is possible to track changes in mastery, performance-approach, and performance-avoidance goals over time (Corker, Donnellan \& Bowles, 2013; Fryer \& Elliot, 2007; Muis \& Edwards, 2009). Although scholars have studied some predictors of change in individuals' achievement goals (e.g., exam performance; Senko \& Harackiewicz, 2005), they overlooked the dynamics involved by the hierarchical nature of their social environment.

Supervisors' mastery and performance-approach goals have been defined isomorphically to those of subordinates, that is, respectively, as a will to improve their professional competences and as a will to outperform other supervisors (for teachers, see Butler, 2007; for employers, Dragoni, 2005; for coaches, Stephens, 2000). To date the level-1 (i.e., subordinates) and level-2 (i.e., supervisors) streams of achievement goals research have progressed independently of each other. Although no published studies have addressed the issue of supervisors-to-subordinates transmissions of achievement goals over time, two sets of indirect evidence suggest that such a phenomenon could occur: (i) classroom goal structure; (ii) achievement goal contagion.

On the one hand, Ames (1992) has described how educators' practices could generate mastery ( $v s$. performance) classroom goal structure. Mastery-oriented instructors tend to engage in mastery-oriented practices (e.g., Retelsdorf \& Günther, 2011) and trigger the emergence of subordinates' mastery goals over time (Patrick, Kaplan, \& Ryan, 2011). Performance-approach-oriented instructors tend to engage in performance-oriented practices and trigger the emergence of subordinates' performance-approach and -avoidance goals over time (Church, Elliot, \& Gable, 2001). 
On the other hand, Eren (2009) developed a model of achievement goal contagion, whereby learners might infer and endorse the goals of their instructors over time. Thus, students could read their teacher's performance-approach goals via external cues. Then, they would come to endorse performance-approach or performance-avoidance goals, depending on individual factors such as self-efficacy. Importantly, the author raised the possibility that "mastery goals [could not] be included in the achievement goals contagion framework" ( $p$. 240), their expression by instructors being less salient in classroom environment.

The two aforementioned lines of research have paved the way to research on goal socialization, but are limited by two complementary issues. The work on classroom goal structure has primarily focused on subordinate-reported perceptions of supervisors rather than on supervisor-reported measures per se (for a similar point, see Wolters, Fan, \& Daugherty, 2010). The model of achievement goal contagion is mechanistic in nature: Supervisor-tosubordinates goal contagion is conceived of as automatic. Our framework departs from this past research by offering a systematic study of the achievement goals socialization phenomenon, that is, a study of the social processes by which subordinates come to endorse the achievement goals of their supervisor.

Before we formally state our hypothesis, we need to mention three caveats. First, we do not formulate predictions for mastery goals. As previously indicated, supervisors' mastery goals might be less socially discernible for subordinates, as they rely on a self-referencedand not socially situated — standard of competence (Elliot, 1999). Moreover, mastery goals are often expressed for social desirability reasons, with individuals reporting unreliable and overemphasized responses to gain favorable judgement (Dompnier, Darnon, \& Butera, 2009). Second, powerful individuals tend to pursue unequivocal goals (Guinote, 2007), to inhibit alternative goals (Slabu, \& Guinote, 2010), and to resist others' (goals) influence (Galinsky, Magee, Gruenfeld, Whitson, \& Liljenquist, 2008). Although group socialization is generally 
conceived as a mutual influence process, supervisors have more influence on their subordinates than the reverse (for a relevant review, see Feldman, 1994). Thus, it is reasonable to assume that supervisors pursue goals that are relatively unaffected by the social environment and remain constant over time. Third, holding a position of power is associated with the activation of the behavioral approach system (Keltner, Gruenfeld, \& Anderson, 2003), with a sensitivity to rewards rather than to threats (Smith \& Bargh, 2008), and with the endorsement of approach rather than avoidance goals (Willis \& Guinote, 2011). As a matter of fact, leaders tend to have lower performance-avoidance goals than performance-approach goals (for an illustration, see Hendricks \& Payne, 2007). Thus, supervisors' performanceavoidance goals are not considered in the present research.

Given the reviewed literature and the above caveats, we formulate a general performance goals socialization hypothesis and its corollary, tested in Study 1 (for a graphical representation, see Figure 1, first panel from the top): The higher a supervisor's performanceapproach goals, the stronger the effects of the time on subordinates' performance-approach goals (Hypothesis 1a) and, by extension, on performance-avoidance goals (Hypothesis 1b).

\subsection{The Consequences of Performance Goals Socialization}

Performance-approach and -avoidance goals may have detrimental consequences over time. Performance-approach goals are associated in the long run with lower reports of motivation for low-achievers (Harackiewicz, Barron, Tauer, \& Elliot, 2002), a shortage of salesmen's efforts (VandeWalle, Brown, Cron, \& Slocum, 1999), or a lack of involvement in sport trainees (Papaioannou, Bebetsos, Theodorakis, Christodoulidis, \& Kouli, 2006).

Likewise, performance-avoidance goals are associated in the long run with students' dissatisfaction (Tuominen-Soini, Salmela-Aro, \& Niemivirta, 2012), workers' progressive disinterest in their job (Tanaka, Okuno, \& Yamauchi, 2013), or athletes' exacerbated focus over mistakes (Stoeber, Stoll, Pescheck, \& Otto, 2008). These studies suggest that students', 
workers', and athletes' performance-based goals predict a decrease in their motivation or well-being. We argue that such a decline could stem from supervisors' performance-approach goals.

Only a few studies adopted a cross-level perspective when testing the effects of supervisors' achievement goals on subordinate-related outcomes. Preenen, Vianen, and Pater (2014) showed that managers' performance-approach goals were negatively related to their employees' experience of challenge while being assigned a task. Barić (2007) reported that coaches' performance-approach goals were negatively associated to their players' investment and enjoyment. Franklin, Porter, and Swider (2013) showed that leaders' performanceapproach goals negatively predicted team task commitment. These studies provide preliminary evidence that supervisors' performance-approach goals may negatively predict subordinates' motivation or well-being. We argue that such a negative influence might be accounted for by performance goals socialization.

Thus, we formulate an exploratory hypothesis and its corollary, examined in Study 2 (for a graphical representation, see Figure 1, second panel from the top): A supervisor's performance-approach goals may predict the evolution of subordinates' pattern of motivation and well-being over time, through the emergence of subordinates' performance-approach goals (Hypothesis 2a) and, by extension, performance-avoidance goals (Hypothesis 2b).

\subsection{The Enabling Condition of Performance Goals Socialization}

Socialization is the process by which individuals acquire the values, attitude, and goals present in one's group (Moreland \& Levine, 1982). A series of studies suggested that group supervisors might be agents of socialization. Newcomb (1943) reported that professors contribute to the progressive increase in the liberal attitudes of their students, and their maintenance over the course of the lifespan (25 years after: Newcomb, Koenig, Flacks, \& Warwick, 1967; 50 years after: Alwin, Cohen, \& Newcomb, 1991). Grojean, Resick, Dickson 
and Smith (2004) discussed the fact that managers can relay specific ethical norms and transmit individualistic values to their followers. Steinfeldt and colleagues (2011) showed that coaches convey masculinity values, such as competitiveness, to their players.

Self-categorization theory describes the three steps involved in such socialization processes (Turner, Hogg, Oakes, Reicher, \& Wetherell, 1987; for an historical review, see Hornsey, 2008). First, individuals categorize themselves as members of a particular social group (e.g., a pupil identify with his/her class). Second, individuals recognize the typical values, attitudes, or goals of their group (e.g., a pupil notice that competition is valued in his/her class). Third, individuals internalize these values, attitudes, or goals (e.g., a pupil embrace the competitive values of his/her class). Thus, self-categorization as a group member (or social identification) is the first and foremost condition for the acquisition and the internalization of group-based values, attitudes, and goals. Accordingly, when one identifies with his/her group, socialization is more likely to arise (Terry \& Hogg, 1996). For instance, from the first to the fourth year of their training program, military students who strongly identified as military officers were found to espouse the group-based dominant beliefs, whereas military students who weakly identified as officers tended to maintain their beliefs (Guimond, 2000). Likewise, employees with a high organizational identification are more likely to embody the same values and goals as their managers than those with a low organizational identification (Martin \& Epitropaki, 2001).

Thus, we argue that supervisor-to-subordinates transmission of performance-based goals corresponds to the same process as any supervisor-based socialization. Subordinates' ingroup identification is posited to be the enabling condition of the recognition (and integration) of supervisors' performance-approach goals. As in prior work on socialization, social identification is therefore conceived as a moderating variable: With time, high-identifiers should be more likely than low-identifiers to endorse the goals of the agent of socialization 
(see Gatto, Dambrun, Kerbrat, \& De Oliveira, 2010; McAuliffe, Jetten, Hornsey, \& Hogg, 2003; Wenzel, 2004). Thus, we formulate a moderation hypothesis and its corollary, tested in Study 3 (for a graphical representation, see Figure 1, third panel from the top): Over time, the higher subordinates' group identification, the stronger the effects of supervisor's performance-approach goals on subordinates' performance-approach goals (Hypothesis 3a) and, by extension, performance-avoidance goals (Hypothesis 3b).

\subsection{The Direction of Performance Goals Socialization}

Elliot and Church (1997) showed that high competence expectancies were an antecedent of performance-approach goals, whereas low competence expectancies were an antecedent of performance-avoidance goals. More recently, Law, Elliot and Murayama (2012) reported that when perceived competence is high, performance-approach goals are pursued unencumbered by performance-avoidance goals, whereas when perceived competence is low, performance-approach and performance-avoidance goals tend to be pursued simultaneously. In the same vein, Senko and Harackiewicz (2005, Study 1) reported that high exam performance (i.e., a positive competence feedback) was associated with a subsequent increase in performance-approach goals, whereas poor early exam performance (i.e., a negative competence feedback) was associated with a subsequent increase in performance-avoidance goals (see also Jagacinski, Kumar, Boe, Lam, \& Miller, 2010).

A series arguments lead us to think that perceived self-competence could determine whether performance goals socialization results in strengthening performance-approach or performance-avoidance goals. Wolter (2004) showed that the perception of classroom performance goals structure is positively associated with the emergence of both performanceapproach and -avoidance goals. Moreover, Urdan and Schoenfelder (2006) suggested that students embedded in such a structure and who are confident in their ability should develop performance-approach goals, whereas students who doubt their ability should develop 
performance-avoidance goals. Likewise, Murayama and Elliot (2012a, 2012b) showed that structural and perceived competition increase concerns about one's normative standing and that individuals regulate these concerns by pursuing performance-approach and performanceavoidance goals. They also suggested that perceived competence could operate as a moderator: Individuals perceiving themselves as being sufficiently competent to face the demand of competition appraise the situation as a challenge and should endorse performanceapproach goals; conversely, individuals perceiving themselves as being insufficiently competent appraise the situation as a threat and should endorse performance-avoidance goals.

As supervisors' performance-approach goals create a social environment conducive to competition, it is legitimate to think that subordinates perceiving themselves as competent may come to endorse performance-approach goals (winning the competition), whereas those perceiving themselves as incompetent may come to endorse performance-avoidance goals (not losing the competition). Thus, we formulate a fourth, second-order interaction hypothesis and its corollary, tested in Study 4 (see Figure 1, fourth panel from the top): Over time, the higher subordinates' perceived self-competence, the stronger the effect of supervisor's performance-approach goals on subordinates' performance-approach goals (Hypothesis 4a) and, by extension, the weaker the effect on subordinates' performance-avoidance goals (Hypothesis 4b).

\section{Study 1. Coaches and Soccer Players}

\subsection{Method}

2.1.1. Participants and procedure. One hundred and fifty-eight players of Swiss amateur soccer teams and their 14 coaches filled in a questionnaire prior to their weekly training session. Five players were excluded due to missing data and two others due to impossibly extreme values on the time variable. The final sample consisted of $N=151$ players (level 1 : 140 men and 11 women; $\left.M_{\text {age }}=22.66, S D=10.17\right)$ nested in $K=14$ male coaches (level 2 : 
$M_{\text {age }}=40.9, S D=14.5 ;$ seniority, $M=3$ years, $S D=2.53 ; n=10.8$ players per coach, $\min =5$, $\max =16)$

\subsubsection{Measures.}

Coaches' achievement goals (level 2). From 1 ("not at all") to 7 ("completely"), coaches answered six items, extracted from Elliot and McGregor's (2001) Achievement Goal Questionnaire (AGQ; validated in French by Darnon and Butera, 2005). Items were adapted to fit the domain of sport. Three items measured mastery-approach goals (e.g., "When I coach my team, I want to improve my training methods as much as possible"; $\alpha=.84, M=6.26, S D$ $=1.23$ ) and three measured performance-approach goals (e.g., "When I coach my team, it is important for me to do better than other coaches"; $\alpha=.89, M=4.14, S D=2.01$ ).

Soccer players' achievement goals (level 1). Using the same response scale, players also answered items adapted from the AGQ. Three items measured mastery-approach goals (e.g., "When I play soccer, I want to learn the sport techniques as much as possible"; $\alpha=.80$, $M=5.67, S D=1.32, s k=-1.00)$, three measured performance-approach goals (e.g., "When I play soccer, it is important for me to play better than the players of the other teams"; $\alpha=.74$, $M=5.58, S D=1.30, s k=-1.19)^{2}$, and three measured performance-avoidance-goals (e.g., "When I play soccer, I just want to avoid playing poorly; .60, $M=4.57, S D=1.42$, sk = $0.36)$

Number of years under the supervision of the coach (level 1). In an open-ended question, players reported "the date from which [they] have been playing with [their] actual coach." The variable was transformed in number of years $(M=1.68, S D=2.16)^{3}$. We refer to this variable as "time." We use this label invariably across studies.

\subsection{Results}

Predictors, coefficient estimates, and confidence interval are presented in Table 1. 
2.2.1. Multilevel modeling procedure and preliminary analysis. We aimed at testing the cross-level interaction effects between coaches' performance-approach goals and time on the three goal outcomes (players' mastery, performance-approach, and -avoidance). We built three multilevel models (one per goal outcome). Each model included the following three grand-mean centered predictors: coaches' performance-approach goals, time, and the interaction (see Supplementary Material for the details of the procedure).

Three sets of preliminary analysis were conducted. First, we tested the effects of coaches' mastery goals (no effects reached significance). Second, we tested the effects of the quadratic term of time to account for potential floor/ceiling effects (an effect was observed for performance-avoidance goals and we kept the term for this outcome). Third, we ran a complete analysis of covariance to determine the need for controlling other covariates (we decided not to keep any of them; see Supplementary Material for the details of the analysis).

\subsubsection{Socialization of achievement goals.}

Players' mastery goals. No effect reached significance ( $p \mathrm{~s} \geq .25)$.

Players' performance-approach goals. Consistent with Hypothesis 1a, the interaction was significant, $B=0.07,95 \% \mathrm{CI}[0.03,0.11]^{4}, Z=3.71, p<.001$. As reported in Figure 2 (left panel), time was more positively associated with subordinates' performance-approach goals when coaches' performance-approach goals were high, $B=0.15, R S E=0.03, Z=5.04$, $p<.001$, than when they were low, $B=-0.14[-0.27,-0.02], Z=-2.22, p=.026$.

Players' performance-avoidance goals. In line with Hypothesis $1 \mathrm{~b}$, the interactions between coaches' performance-approach goals and time were significant for the linear term, $B$ $=0.07[0.01,0.13], Z=2.32, p=.02$, and for the quadratic term, $B=-0.03[-0.04,-0.01], Z=$ $-3.33, p<.001$. As reported in Figure 2 (right panel), time was more positively associated with subordinates' performance-avoidance goals when coaches' performance-approach goals were high (for the linear term: $B=0.14[-0.10,0.37], Z=1.15, p=.25$; for the quadratic term: 
$B=-0.05[-0.09,-0.01], \mathrm{Z}=-2.62, p=.009)$ than when they were low (for the linear term: $B$ $=-0.17[-0.28,-0.06], Z=-2.95, p=.003$; for the quadratic term: $B=0.06[0.03,0.10], Z=$ $3.59, p<.001)$.

\subsection{Discussion}

In line with Hypothesis 1a, Study 1 showed that the higher the supervisors' performance-approach goals (in this case, coaches), the stronger the effects of time on subordinates' performance-approach goals (in this case, soccer players). In line with Hypothesis 1b, results revealed the same phenomenon for subordinates' performanceavoidance goals, notwithstanding the intervention of a floor effect (for supervisors endorsing low performance-approach goals) and a ceiling effect (for supervisors endorsing high performance-approach goals). This unexpected polynomial interaction suggests a somehow faster performance goals socialization for performance-avoidance goals (reaching their minimum / maximum more rapidly than performance-approach goals). Moreover, achievement goals socialization was only found for performance goals: Supervisors' mastery goals did not significantly interact with time in predicting soccer players' mastery, performance-approach or performance-avoidance goals.

Given the cross-sectional nature of Study 1, we cannot rule out the possibility that the results are (partially) due to a (self-)selection process rather than a socialization process: When having a different level of performance-based goals than supervisors, subordinates may be excluded from (or leave) the group (see Bachman, Sigelman, \& Diamond, 1987). This issue is addressed in Study 4. Additionally, two limitations point out the need for replication. First, while sample size at level 1 was satisfactory, at level 2, it was low. Second, Study 1 took place in a sport setting. The processes of achievement goals socialization was not expected to depend on the achievement domain, and therefore Study 2 aimed to replicate 
Study 1's findings within more numerous academic groups, while also exploring Hypotheses $2 \mathrm{a}$ and $2 \mathrm{~b}$.

\section{Study 2. Thesis Supervisor and Ph.D. Students}

\subsection{Method}

3.1.1. Participants and procedure. Seventy-nine Ph.D. students of two Swiss universities (Social and Technical Sciences) and their 41 thesis supervisors filled in an online questionnaire. Eight Ph.D. students were excluded due to missing data and another one was identified as an outlier ${ }^{5}$. The final sample consisted of $N=70$ students (level 1: 37 social sciences students and 33 technical sciences students; 45 men and 25 women; $M_{\text {age }}=28.39, S D$ $=3.61$ ) nested in $K=41$ thesis supervisors (level 2: 38 men and 3 women; $n=1.7$ students per supervisor, $\min =1, \max =5)$.

\subsubsection{Measures.}

Thesis supervisors' achievement goals (level 2). As in Study 1, thesis supervisors answered items adapted from the AGQ. This time, items were adapted to fit the academic domain. Three items measured mastery-approach goals (e.g., "In my research work, I want to learn as much as possible about my subject"; $\alpha=.89, M=6.49, S D=0.56$ ) and three measured performance-approach goals (e.g., "In my research work, my goal is to have more publications than most other researchers"; $\alpha=.81, M=3.76, S D=1.22$ ).

Ph.D. students' achievement goals (level 1). Ph.D. students also answered items adapted from the AGQ. Three items measured mastery-approach goals (e.g., "In my thesis work, I want to learn as much as possible about my subject"; $\alpha=.53^{6}, M=6.52, S D=0.50, s k$ $=0.18$ ), three measured performance-approach goals (e.g., "In my thesis work, it is important for me to do better than other Ph.D. students; $\alpha=.92, M=3.34, S D=1.51, s k=-0.83$ ) and three measured performance-avoidance-goals (e.g., "In my thesis work, I just want to avoid doing poorly"; $\alpha=.72, M=3.46, S D=1.44, s k=-0.01$ ). 
Number of years Ph.D. student spent under the supervision of the director (level 1). In an open-ended question, Ph.D. students reported "when did [they] start [their] Ph.D.," which was transformed in number of years $(M=2.42, S D=1.49)$.

Ph.D. students' intention to drop out of thesis. From 1 ("not at all") to 7 (“completely"), students answered two items (e.g., "I often think about quitting my thesis in a near future"; $\alpha=.55, M=2.29, S D=1.37, s k=-0.74)$, extracted from the Michigan Organizational Assessment Questionnaire (Cammann, Fichman, Jenkins, \& Klesh, 1979).

Ph.D. students' satisfaction. From 1 (“not at all") to 7 (“completely"), Ph.D. students answered the five items of the Bacharach, Bamberger and Conley's (1991) Job Satisfaction Scale (e.g., "In my thesis, I am satisfied of my research work in light of my career expectations"; $\alpha=.82, M=4.86, S D=1.14, s k=0.75){ }^{7}$

\subsection{Results}

\subsubsection{Replication of Study 1's findings.}

Predictors, coefficient estimates, and confidence intervals are presented in Table 2.

Multilevel modeling procedure and preliminary analysis. Again, we aimed at testing the cross-level interaction effects between thesis supervisors' performance-approach and time on the three goal outcomes. As the intraclass coefficient correlations and the between-cluster variations of the effect of time were not significantly different from zero, we built three standard regression models with standard errors adjusted for clustering (one per goal outcome). Each model included the following four grand-mean centered predictors: coaches' performance-approach goals, time, the interaction, as well as university affiliation (to account for potential sample effects; coded "- 0.5 " for "Social Science" and " +0.5 " for "Technical Science"; see Supplementary Material for the details of the procedure).

Two sets of preliminary analyses were conducted. First, we tested the effects of coaches' mastery goals (no effect reached significance). Second, we ran a complete analysis 
of covariance to determine the need for controlling other covariates (no effect reached significance; see Supplementary Material for the details of the analysis).

Ph.D. students' mastery goals. No effect reached significance ( $p s \geq .31)$.

Ph.D. students' performance-approach goals. Consistent with Hypothesis 1a, the interaction between supervisors' performance-approach goals and time was significant, $B=$ $0.20[0.03,0.38], Z=2.26, p=.024$ (al path in Figure 3). As in Study 1, time was more positively associated with subordinates' performance-approach goals when supervisors' performance-approach goals were high, $B=0.20[-0.10,0.49], Z=1.30, p=.20$, than when they were low, $B=-0.30[-0.64,0.05], Z=-1.68, p=.093$.

Ph.D. students' performance-avoidance goals. Consistent with Hypothesis $1 \mathrm{~b}$, the interaction between supervisors' performance-approach goals and time was significant, $B=$ $0.15[0.04-0.26], Z=2.70, p=.007$ (a2 path in Figure 3). As in Study 1, time was more positively associated with subordinates' performance-avoidance goals when supervisors' performance-approach goals were high, $B=0.10[-0.09,0.30], Z=1.01, p=.31$, than when they were low, $B=-0.27[-0.54,0.00], Z=-1.94, p=.052$.

\subsubsection{Consequences of performance goals socialization.}

Predictors, coefficient estimates, and confidence intervals are presented in Table 3.

\section{Ph.D. students' intention to drop out of thesis.}

Total effect of supervisors' performance-approach goals over time. As a first step, we aimed at exploring the consequences over time of supervisors' performance-approach goals on Ph.D students' intention to drop out of thesis. We built a multilevel model including the same four predictors as before (see Supplementary Material for the details of the procedure). The interaction between supervisors' performance-approach goals and time was significant, $B$ $=0.19[0.05,0.33], Z=2.67, p=.008(c 1$ path in Figure 3). As reported in Figure 4 (left panel), time was more positively associated with intention to drop out when supervisors' 
performance-approach goals were high, $B=0.73[0.51,0.94], Z=6.68, p<.001$, than when they were low, $B=0.26[-0.01,0.53], Z=1.92, p=.05$.

Indirect effect of supervisors' performance-approach goals through Ph.D. students' goals. As a second step, we aimed at determining the potential role of Ph.D. students' achievement goals in explaining the interaction between supervisors' performance-approach goals and time on intention to drop out. All grand-mean centered students' achievement goals and their interactions were included in the $\operatorname{model}^{8}$. The interaction between supervisors' performance-approach goals and time remained the same, $B=0.18[0.05,0.31], Z=2.71, p$ $=.007\left(\mathrm{cl}\right.$ ' path in Figure 3) ${ }^{9}$. More importantly, Ph.D. students' performance-approach goals were positively associated with intention to drop out, $B=0.18[0.03,0.34], Z=2.37, p<.018$ (b1 path in Figure 3). As Ph.D. students' performance-approach goals could be a good candidate in explaining the moderation effect between supervisors' performance-approach goals and time on students' intention to drop out, the indirect effect was calculated using Monte Carlo simulations (MacKinnon, Lockwood, \& Williams, 2004) ${ }^{10}$. It was $B=0.02$ [0.001, 0.093] $(a 1 * b 1$ path in Figure 3).

\section{Ph.D. students' satisfaction.}

Total effect of supervisors' performance-approach goals over time. In a first step, we built the same multilevel model used for intention to drop out, but this time predicting students' satisfaction (see Supplementary Material for the details of the procedure). The interaction between thesis supervisors' performance-approach goals and time was significant, $B=-0.26[-0.40,-0.13], Z=-3.76, p<.001$ ( $c 2$ path in Figure 3). As it can be seen in Figure 4 (right panel), time was more negatively associated with satisfaction when supervisors' performance-approach goals were high, $B=-0.25[-0.45,-0.05], Z=-2.40, p=.016$, than when they were low, $B=0.39[0.13,0.66], Z=2.89, p=.004$. 
Indirect effect of supervisors' performance-approach goals through Ph.D. students'

goals. In a second step, we aimed at determining the potential role of Ph.D. students' achievement goals in explaining the interaction between thesis supervisors' performanceapproach goals and time on satisfaction. All grand-mean centered Ph.D. students' achievement goals and their interactions were included in the model. The interaction between supervisors' performance-approach goals and time remained the same, $B=-0.25,[-0.38$, 0.12], $Z=-3.91, p<.001$ ( $c 2$ ' path in Figure 3). More importantly, Ph.D. students' performance-avoidance goals were negatively associated with their satisfaction, $B=-0.18$ [$0.33,-0.02], Z=-2.22, p=.026$ ( $b 2$ path in Figure 3 ). The indirect effect of supervisors' performance-approach goals on satisfaction via performance-avoidance goals was $B=-0.02$ [$0.061,-0.001](a 2 * b 2$ path in Figure 3).

\subsection{Discussion}

Consistent with what observed in Study 1, but for a different achievement domain, Study 2 showed that the higher the supervisors' performance-approach goals (in this case, thesis supervisors), the stronger the effects of time on subordinates' (in this case, Ph.D. students) performance-approach (Hypothesis 1a) and performance-avoidance (Hypothesis 1b) goals. Contrasting with Study 1, the polynomial interaction between supervisors' performance-approach goals and time was not significant. The tighter range of our time variable might explain such an absence of floor / ceiling effect.

Beyond the replication of performance goals socialization, Study 2 provided an illustration of its consequences. First, in line with Hypothesis 2a, Study 2 showed that supervisors' performance-approach goals were directly and indirectly-through subordinates' performance-approach goals - associated with intention to drop out. These findings are consistent with the one establishing a positive relationship between performance goal climate and dropout behaviors (Sarrazin, Vallerand, Guillet, Pelletier, \& Cury, 2002). However, the 
valence of the performance goals mediator is surprising, as individuals' performanceapproach (vs. -avoidance) goals have been found to positively predict persistence (Elliot et al., 1999). This could be explained by the specificity of our participants (i.e., Ph.D. students), who are often expected to work on complex scientific material (e.g., state-of-the-art findings) in collaboration with others (e.g., with co-authors). When conducting difficult task within groups, performance-approach goals typically impair team adaptation (LePine, 2005), which could favor disengagement and dropout (Rumberger, 2001).

Second, in line with Hypothesis 2b, Study 2 showed that, over time, supervisors' performance-approach goals were directly and indirectly — through subordinates' performance-avoidance goals — associated with satisfaction. These findings are consistent with research reporting a negative relationship between performance goal climate and satisfaction (Treasure \& Robert, 2001), and a negative effect of performance-avoidance goals on satisfaction (Diseth \& Samdal, 2014).

Now that we have empirically defined performance goals socialization and identified (some of) its consequences, we intend to show that this phenomenon is indeed a socialization process. Since self-categorization is the prerequisite for socialization processes to occur, we expect identification to one's group to be the enabling condition of performance goals socialization. Specifically, after having spent a substantial amount of time in a group led by a performance-approach-oriented supervisor, subordinates highly (vs. poorly) identified with their group should pursue more performance-approach goals (Hypothesis 3a) and performance-avoidance goals (Hypothesis 3b). This idea was tested in another achievement setting, albeit more informal: video game teams (see Ryan, Rigby, \& Przybylski, 2006). 


\section{Study 3. Video Game Team Leaders and Players}

\subsection{Method}

4.1.1. Participants and procedure. Sixty-six players from 24 teams of an online multiplayer video game filled in an online questionnaire. The video game is an online first-person shooter named "Quake Live." The particularity of the teams from this game is to be hierarchically structured. Each member has an explicit status: Initiate, Member, Veteran, Clan Leader, and Clan Officer (from the lowest to the highest rank). The latter two ranks allow the players to invite new members to join the team, and to promote, demote or exclude existing members. The Clan Officers (or Clan Leaders in the case of teams having no Clan Officer) were treated as supervisors, whereas the players having inferior ranks were treated as subordinates. Eight participants were excluded due to missing data or because they were not yet in the team at the time of data collection. The final sample consisted of $N=33$ team-member (level 1: 32 men and 1 woman; $\left.M_{\text {age }}=24.09, S D=4.46\right)$ nested in $K=25$ leaders (level 2: 24 males and 1 missing value; $M_{\text {age }}=25.74, S D=3.56 ; n=1.4$ team-member per leader, $\left.\min =1, \max =4\right)^{11}$.

\subsubsection{Measures.}

Leaders' performance-approach goals (level 2). As in Studies 1 and 2, leaders answered items adapted from the AGQ. This time, items were adapted to fit the area of video games. Only the three items measuring performance-approach goals were considered (e.g., "When I play, I want to perform better than the other players."; $\alpha=.81, M=5.29, S D=1.16$ ). As in Studies 1 and 2 supervisors' and subordinates' mastery goals were not found to produce consistent results and these goals were no longer considered.

Team-members'performance goals (level 1). Team-members answered the same performance goals items as their leaders. Three items measured performance-approach goals $(\alpha=.56, M=5.21, S D=1.01, s k=-0.20)$ and three measured performance-avoidance goals 
("When I play, I want to avoid being worse than the other players."; $\alpha=.82, M=4.71, S D=$ $1.68, s k=-0.65)$.

Team-members' identification with their team (level 1). From 1 ("not at all") to 7 (“completely"), each team-member answered three items adapted from Falomir-Pichastor, Mugny, Invernizzi, Di Palma and Estrada (2007); i.e., "Do you identify with your clan?”; “Do you feel close to the members of your clan?"; and "Do you think you're similar to the members of your clan?"; $\alpha=.85, M=5.50, S D=1.09$.

Time team-members spent under the supervision of the leader (level 1). During the completion of the questionnaire, the date on which team-members joined their team was collected. This information was publicly accessible via the players' game statistics profile. The variable was transformed in number of months $(M=10.73, S D=9.94)$.

Team-members' average game performance (level 1). As performance was reported as an antecedent of achievement goals (Senko \& Harackiewicz, 2005) and could be confounded with the effect of leaders' performance-approach goals, team-members' average accuracy was used as a measure of performance. This measure was collected on players' game statistics profile. It was an average percentage for all games and could range from $0 \%$ (perfect inaccuracy: Each time the participant shoots, s/he misses the opponent) to $100 \%$ (perfect accuracy: Each time the participant shoots, s/he hits the opponent; $M=29.18, S D=$ 6.39).

\subsection{Results}

Predictors, coefficient estimates, and confidence interval are presented in Table 4.

4.2.1. Multilevel modeling procedure and preliminary analysis. Again, we aimed at testing (second order) cross-level interaction effects. We built two multilevel models (one per goal outcome). Each model included the following eight grand-mean centered predictors: leaders' 
performance-approach goals, time, team-members' identification, and the interactions (see Supplementary Material for the details of the procedure).

As in Studies 1 and 2, we ran a complete analysis of covariance to determine the need for controlling other covariates (an effect of team-members' performance was observed for both performance-based goals and we kept the term; see Supplementary Material for the details of the analysis).

Team-members' performance-approach goals. Consistent with Hypothesis 3a, the three-way interaction between leaders' performance-approach goals, time, and members' identification was significant, $B=0.05[0.004,0.09], Z=2.13, p=.033$. As shown in Figure 5 (left panel), when time was high $(+1 S D)$, the interaction between leaders' performanceapproach goals and members' identification was significant, $B=0.59[0.02,1.15], Z=2.02, p$ $=.043$, whereas this was not the case when it was low $(-1 S D), B=-0.37[-0.81,0.07], Z=-$ $1.63, p=.103$. Specifically, when time was high, leaders' performance-approach goals were more positively associated with subordinates' performance-approach goals when subordinates were highly identified (+1 SD), $B=0.41[-0.41,1.24], Z=0.98, p=.327$, than when they were poorly identified (-1 SD), $B=-0.86[-1.66,-0.06], Z=-2.11, p=.035$. The three-way interaction is plotted in an alternative way (a 3-D surface chart) in Supplementary Material.

Team-members' performance-avoidance goals. Consistent with Hypothesis $3 b$, the three-way interaction between leaders' performance-approach goals, time, and members' identification was significant, $B=0.06[0.01,0.10], Z=2.50, p=.012$. As shown in Figure 5 (right panel), when time was high $(+1 S D)$, the interaction between leaders' performanceapproach goals and members' identification was significant, $B=0.86[0.35,1.36], Z=3.34, p$ $<.001$, while this was not the case when it was low $(-1 S D), B=-0.29[-0.87,0.29], Z=0.99$, $p=.324$. Specifically, leaders' performance-approach goals were more positively associated with subordinates' performance-avoidance goals when subordinates were highly identified 
$(+1 S D), B=1.06[0.19,1.93], Z=2.38, p=.017$, than when they were poorly identified $(-1$

SD), $B=-0.81[-1.77,0.15], Z=-1.65, p=.098$. The three-way interaction is plotted in an alternative way (a 3-D surface chart) in Supplementary Material.

\subsection{Discussion}

Extending the findings of Studies 1 and 2, and consistent with Hypotheses $3 \mathrm{a}$ and 3b, Study 3 showed that, over time, the higher the subordinates' identification with their group (in this case, video game team-members), the stronger the effects of supervisors' performanceapproach goals (in this case, team leaders) on performance-approach goals (Hypothesis 3a) and performance-avoidance goals (Hypothesis 3b). Thus, the enabling condition of supervisor-to-subordinate performance goal transmission is the same as that of any socialization: Self-categorization is the condition for subordinates' performance-based goal to be influenced by those of their supervisors.

In sum, the moderating role of identification implies that performance goals socialization is truly an in-group process. For high identifiers, performance-approach-oriented supervisors promote performance-approach and -avoidance goals, which may have various downstream consequences on subordinates' attitudes and behaviors (e.g., on persistence, as in Study 2; see also, Elliot et al., 1999). For low-identifiers, performance-approach-oriented supervisors have a more limited influence, which may counteract the potential deleterious effects (or cancel out the potential beneficial effects) of performance goals socialization.

One might wonder whether the performance goals socialization effects-although moderated by group identification processes - actually correspond to a progressive endorsement of goals over time (i.e., a socialization effect) or to the fact that subordinates not pursuing the same goals as their supervisors are eventually excluded from (or decide to leave) the group (i.e., a (self-)selection effect; Bachman et al., 1987). Study 4 used a longitudinal design to rule out this alternative possibility. 
Another important issue remains unaddressed. In Studies 1 to 3, supervisors' performance-approach goals were found to be associated with the emergence of both subordinates' performance-approach and -avoidance goals over time. Yet, these two goals are distinct constructs and produce competing effects (Murayama, Elliot, \& Yamagata, 2011). It is therefore critical to specify when supervisors' performance-approach goals predict one or the other. Since high perceived self-competence is an antecedent of performance-approach goals and low self-competence is an antecedent of performance-avoidance goals (for a review, see Murayama \& Elliot, 2012b), we expected perceived self-competence to be the directional moderator of performance goals socialization. Supervisors' performance-approach goals should prompt performance-approach goals for subordinates perceiving themselves as being sufficiently competent (Hypothesis 4a) and performance-avoidance goals for subordinates perceiving themselves as being insufficiently competent (Hypothesis $4 \mathrm{~b}$ ). This idea was tested in a fourth type of achievement setting, namely secondary education.

\section{Study 4. Schoolteachers and Pupils}

\subsection{Method}

5.1.1. Participants. $N_{\mathrm{T} 1}=625$ French middle school students and their 25 teachers concurrently took part in the first wave of the study. $N_{\mathrm{T} 2}=496$ of the first-wave pupils whose teacher(s) participated fully completed the second wave questionnaire. One teacher was removed due to incomplete data. The final pupil sample consisted of 496 pupils (259 boys and 237 girls; 124 sixth-graders, 124 seventh-graders, 139 eight-graders, and 109 ninth-graders; $\left.M_{\text {age }}=13.16, S D=1.19\right)$. The final teacher sample consisted of 24 teachers ( 7 men and 17 women; $M_{\text {age }}=41.0, S D=11.04$; years of seniority, $M=15.06$ years, $S D=11.42 ; 20.7$ pupils per teacher, $\min =5, \max =44)$.

\subsubsection{Procedure.}


Wave 1. At the beginning of the school year (i.e., late September), two experimenters submitted a first questionnaire to the pupils of a French middle school. Parents were informed by mail about the general purpose of the study two weeks before. All except four pupils were allowed to participate in the study. The Wave 1 questionnaire measured pupils' achievement goals and perceived self-competence in six disciplines, namely Mathematics, First Foreign Language, French, Physical Education, History and Geography, and Earth and Life Science. Additionally, pupils were asked whether or not "[they] knew [their] teacher before this school year" for the six same disciplines (1435 negative answers, 585 positive ones, and 40 missing). At the same time, the teachers in the six aforementioned disciplines (6 in Mathematics, 6 in First Foreign Language, 5 in French, 3 in Physical Education, 2 in History and Geography, and 2 in Earth and Life Science) reported, in a paper-and-pencil or on-line questionnaire, their performance-approach goals for teaching ${ }^{12}$. In sum, there were $N=2060$ discipline-based units (level 1), both nested in $K_{2 \mathrm{a}}=496$ pupils (level 2a; $n_{2 \mathrm{a}}=4.2$ observations per children) and in $K_{2 \mathrm{a}}=24$ teachers (level $2 \mathrm{~b} ; n_{2 \mathrm{~b}}=85.83$ observations per teacher).

Wave 2. Four months later (i.e., late January), two experimenters invited the pupils to fill in a second questionnaire, once again measuring their goals for the same six disciplines.

\subsubsection{Measures.}

Teachers' performance-approach goals (level $2 \boldsymbol{b}$ ). In Wave 1, as in Studies 1 to 3, teachers answered items adapted from the AGQ. This time, items were adapted to fit the school domain (e.g., "When I am teaching, it is important for me to teach better as compared to other teachers"; $\alpha=.87, M=2.58, S D=1.61)$.

Pupils' perceived self-competence (level 1). In Wave 1, on a scale ranging from 0 (“"not competent at all") to 100 (“fully competent"), pupils reported their perceived selfcompetence in the aforementioned six disciplines $(M=62.38, S D=25.05)$. For the ease of reading, the variable was divided by $10\left(M^{\prime}=6.24, S D^{\prime}=2.51\right)$. 
Change in pupils' performance goals from Wave 1 to Wave 2 (level 1). For each wave, pupils answered the performance goal items adapted from the AGQ. One of the performance-avoidance items was removed due to reliability issue (i.e., "My fear of performing poorly in this discipline is what motivates me"; as in past research, e.g., Darnon, Harackiewicz, Butera, Mugny, \& Quiamzade, 2007). For each discipline, three items measured performance-approach goals (e.g., "My goal in this discipline is to have better grade than most of others pupils") at Wave 1 (average of the six Cronbach's alpha for all disciplines, $\left.M_{\alpha}=.86, M=4.03, S D=1.89\right)$ and Wave $2\left(M_{\alpha}=.90, M=3.75 S D=1.97\right)$. Change in performance-approach goals was computed by subtracting the latter from the former $(M=-0.29, S D=1.70, s k=0.01)$. Two items measured performance-avoidance goals (e.g., "I just want to avoid doing poorly in this discipline") at Wave $1\left(M_{\alpha}=.58, M=5.84, S D\right.$ $=1.46)$ and Wave $2\left(M_{\alpha}=.71, M=5.64, S D=1.62\right)$. Change in pupils' performanceavoidance goals was also computed by subtracting the latter from the former $(M=-0.20, S D=$ $1.60, s k=-0.22){ }^{14}$

\subsection{Results}

Predictors, coefficient estimates, and confidence interval are presented in Table 5.

\subsubsection{Multilevel modeling procedure and preliminary analysis. In the present data,} discipline-based observations were cross-classified by pupils and teachers. Thus, we built two cross-classified multilevel models (one for change in pupils' performance-approach goals and another for change in pupils' performance-avoidance goals). Each model included the following four grand-mean centered predictors: teachers' performance-approach goals, pupils' perceived self-competence, the interaction, as well as change in pupils' performanceavoidance goals when the outcome was performance-approach goals, and vice versa (to disentangle the effects of one goal from the effect of the other; see Supplementary Material for the details of the procedure). ${ }^{13}$ 
As in Studies 1-3, we ran a complete analysis of covariance to determine the need for controlling additional covariates. We observed an effect of the fact that the teacher was known before the school year on change in pupils' performance-avoidance goals (the covariates was coded "- 0.5 " for "teacher unknown" and " +0.5 " for "teacher known" and is referred to as teacher familiarity). Thus, the term was kept for this outcome (see Supplementary Material for the details of the analysis).

5.2.3. Change in pupils' performance-approach goals. The intercept was found to be significantly different from zero, $B=-0.29[-0.41,-0.17], Z=-4.67, p<.001$, suggesting a general decrease of pupils' performance-approach goals from Wave 1 to Wave 2. More importantly, in line with Hypothesis 4a, the analyses revealed an interaction between teachers' performance-approach goals and pupils' perceived self-competence, $B=0.02[0.01,0.04], Z=$ 2.94, $p=.003$. As shown in Figure 6 (left panel), when perceived self-competence was high (+1 SD), teachers' performance-approach goals were more positively associated with change in performance-approach goals, $B=0.05[0,0.10], Z=1.87, p=.062$, than when perceived self-competence was low (-1 SD), $B=-0.06[-0.12,-0.004], Z=-2.09, p=.037$.

5.2.4. Change in pupils' performance-avoidance goals. The intercept was again found to be significantly different from zero, $B=-0.13[-0.24,-0.02], Z=-2.27, p=.023$, suggesting a general decrease in performance-avoidance goals for Wave 1 to Wave 2. More importantly, the second-order interaction between teachers' performance-approach goals, pupils' perceived self-competence, and teacher familiarity was significant, $B=0.04[0.01,0.07], Z=-2.52, p$ $=.012$. Specifically, the interaction between teachers' performance-approach goals and pupils' perceived self-competence was not significant when the teacher was known before the beginning of the school year, $B=0.02[0,-0.05], Z=1.62, p=.105$, whereas it was significant when s/he was unknown, $B=-0.02[-0.04,-0.001], Z=-2.11, p=.035$. As shown in Figure 6 (right panel), when perceived self-competence was low (-1 SD), teacher's 
performance-approach goals were more positively associated with change in performanceavoidance goals, $B=0.08[0.01,0.14], Z=2.29, p=.022$, than when perceived competence was high (+1 SD), $B=-0.02[-0.07,0.04], Z<|1|, p=.585$.

\subsection{Discussion}

Extending the findings of Studies 1 to 3, and consistent with Hypotheses 4a and 4b, Study 4 showed that perceived self-competence moderated performance goals socialization.

On the one hand, the higher subordinates' perceived self-competence (in this case, middle school students), the stronger the effect of supervisors' performance-approach goals (in this case, teachers) on the change in subordinates' performance-approach goals (Hypothesis 4a). On the other hand, the lower subordinates' perceived self-competence, the stronger the effect of supervisors' performance-approach goals on the change in subordinates' performance-avoidance goals (Hypothesis 4b). However, Hypothesis 4b was confirmed only when pupils did not know their teacher before the beginning of the school year. This unexpected result is coherent with a socialization process, to the extent that it means that pupils who already knew their teacher could have already been socialized. As this difference was not observed for performance-approach goals, it also suggests a somehow faster performance-avoidance ( $v s$. performance-approach) goals socialization (as in Study 1). However, it should be emphasized that we decided to include teacher familiarity as an additional moderator following the preliminary analysis. Thus, the results pertaining to performance-avoidance goals should be considered as exploratory and would require further confirmation using a deductive approach.

In sum, the moderating role of perceived self-competence implies that the outcome of performance goals socialization is not invariable. For subordinates high in self-competence, performance-approach-oriented supervisors prompt the endorsement of performanceapproach goals, which are typically associated with a mixed pattern of adaptive and 
maladaptive outcomes (e.g., high performance but low openness to collaboration; see Senko, Hulleman, \& Harackiewicz, 2011). However, for subordinates low in self-competence, performance-approach-oriented supervisors prompt the endorsement of performanceavoidance goals, which are typically associated with a pattern of maladaptive outcomes (e.g., low performance and interaction anxiety; Valentiner, Mounts, Durik \& Gier-Lonsway, 2011).

One might wonder why a general decline in both performance goals was observed. Shim, Ryan, and Andersen (2008) has reported similar within-school-year decline in all types of achievement goals for $6^{\text {th }}$ and $7^{\text {th }}$ graders. The authors argued that novelty or uncertainty at the beginning of the school year may generally heighten the pursuit of achievement goals. The overall decline in achievement goals might also be due to fall-to-spring change in pupils' concerns about evaluation (Meece \& Miller, 2001) or to a progressive increase of pupils' normative clear-sightedness (Bigot, Pichot, \& Testé, 2004; especially for performance goals which are socially undesirable; Dompnier, Darnon, Delmas, \& Butera, 2008; Pekrun, Maier, \& Elliot, 2006).

\section{General Discussion}

Performance-based goals have high social costs for groups, to the extent that they have been associated with hostile responses to academic disagreements within learning dyads (Sommet et al., 2014), non-cooperative organizational behaviors within work teams (Poortvliet, \& Giebels, 2012), or unsportsmanlike conducts within sport teams (Boardley \& Kavussanu, 2010). It is thus crucial to understand how—in spite of these detrimental costssocial reproduction of these goals operates. In the present research, we focused on the function of group supervisors as agents of performance goals socialization.

Across various achievement domains, four studies provided convergent evidence for performance goals socialization, as well as empirical illustrations of its consequences, enabling condition, and directional moderator. With respect to the phenomenon itself, in a 
first cross-sectional study involving sport teams, coaches' performance-approach goals were found to be positively associated with the emergence of their players' performance-approach and-avoidance goals. With respect to its consequences, in a second cross-sectional study involving academic organizations, thesis supervisors' performance-approach goals were found to be associated with an increase over time (directly and indirectly through the emergence of performance-approach goals) in their Ph.D. students' intentions to drop out and with a decrease over time (directly and indirectly through the emergence of performanceavoidance goals) in their Ph.D. students' satisfaction. With respect to its enabling condition, in a third cross-sectional study involving video game teams, leaders' performance-approach goals were found to be more positively associated with the emergence of performanceapproach and -avoidance goals, as team-members' in-group identification increased. Since self-categorization is needed for goal influence to occur, this result underlines that the phenomenon under study is indeed a form of socialization. With respect to its directional moderator, in a last longitudinal study involving secondary school classrooms, teachers' performance-approach goals were found to be more positively associated with change in performance-approach goals as pupils' perceived competence increased, and with change in performance-avoidance goals as it decreased.

\subsection{Theoretical Contributions}

The first contribution of the present set of studies pertains to the issue of the predictors of performance-based goals. Independently of each other, some scholars addressed this question at a structural level (e.g., group goal structure; Wolter, 2004), while others addressed it at the intrapersonal level (e.g., perceived self-competence; Elliot \& Church, 1997). In adopting an integrative cross-level approach, the findings of Studies 1,2 and 4 allow to articulate these two levels of analysis. At level 2, group-supervisors promote the endorsement of performance-based goals socialization, whereas at level 1, subordinates' perceived self- 
competence is a predictor of the approach vs. avoidance component associated with these performance-based goals. Considering both supervisors' and subordinates' goals, our results extend the work on performance goals adjustment over time (e.g., Kumar \& Jagacinski, 2011; Meece, \& Miller, 2001, Senko \& Harackiewicz, 2005), by showing the importance of taking interpersonal and inter-positional perspectives (studying the (goals) dynamics between individuals different in status; Doise, 1986) in understanding that adjustment (Poortvliet \& Darnon, 2010).

The second contribution of the present set of studies pertains to the place of achievement goals in the literature on socialization. On the one hand, achievement goals theorists have shown that the expression of performance-approach goals depends on the norms of a given social system (Dompnier, Darnon, \& Butera, 2013). On the other hand, group socialization theorists have accumulated evidence that social identification was the sine qua non condition of the social transmission of normative values, attitudes, and goals over time (e.g., Guimond, 2000). Building a bridge between these two literatures, Study 3's findings reveal that the enabling condition involved in performance goals socialization is analogous to that of any socialization process: High-identifiers under the supervision of a performance-approach-oriented leaders may come to recognize performance-based goals as the social-normative achievement goals and come to integrate it. Another implication of such phenomenon is that clear-sighted subordinates under the supervision of a performanceapproach-oriented leader may perceive performance-based goals as socially desirable and endorse them for self-presentation purpose (to gain positive evaluation; see Darnon, Dompnier, \& Poortvliet, 2012). Since supervisors often try to secure compliance and conformity via authority (Michel, Wallace, \& Rawling, 2013), but subordinates often genuinely embrace their group-leaders' goals (Tyler, 2006), future research is needed to determine the extent to which performance goals socialization is a manifest or a latent 
phenomenon (Bender, 1967). These questions notwithstanding, our findings highlight the need to take a structural perspective in understanding the effects of performance goals, that is, studying the (goals) dynamics as a function of social norms (Doise, 1986; Poortvliet \& Darnon, 2010).

\subsection{Applied Contributions}

This research also has an important practical implication: Study 2 shows that performance-approach-oriented supervisors elicit — via performance goals socialization - the emergence of a maladaptive pattern of motivation and well-being (drop out and dissatisfaction). More generally speaking, subordinates' performance goals are not only associated with a series of detrimental intrapersonal behaviors (e.g., long-term learning, Murayama \& Elliot, 2011; for a discussion of their more adaptive outcomes, see Senko et al., 2011), but also with detrimental intragroup behaviors (e.g., hostile, antisocial, uncooperative conducts; see Sommet, Darnon, \& Butera, 2015). Thus, it would seem reasonable to assume supervisors' performance-approach goals to predict-via performance goals socializationdysfunctional regulation of in-group behaviors.

Because of performance goals' elevated social cost for groups, small group researchers argued that these goals should be discouraged within learning groups and formulated practical recommendations. Relying on an individual-level approach, Dierdorff and Ellington (2012) proposed interventions aiming at reducing trainees' focus on normative performance (and by extension performance-based goals). Given our results, one might doubt that performanceoriented trainees could easily be re-socialized, given the permanent presence of their performance-approach-oriented team-leader. However, relying on a structural-level approach, Gully and Phillips (2005) recommend leaders to use feedback and focus the reward system on processes rather than outcomes (thus reducing followers' performance-based goals). Again, given our results, one might doubt that performance-approach-oriented leaders would rely on 
such management practices, as they could conflict with their own goals. For our part, relying on a cross-level approach, we suggest that interventions should be framed in such a way as to reduce supervisors' personal performance-approach goals, therefore resulting in a more profound change in their managing practices. In this regard, Skaalvik and Skaalvik (2013) reported a correlation between teachers' perception of their school performance goals structure (i.e., school emphasizing performance goals) and their personal performanceapproach goals. Policies based on structural changes might reduce the performance goals of supervisors and, through socialization, that of their subordinates.

\subsection{Limitations}

Some limitations should be noted. First, it should be stressed that the samples used in the present study consisted of convenience samples, and replications using more representative samples might provide a hint on the prevalence of performance goals socialization. This limitation notwithstanding, the variety of the contexts of the data collection speaks in favor of a potential generalization of our results: Performance goals socialization was observed in sport teams, academic organizations, video game teams, and middle school classrooms, and is likely to be observed across other social groups.

Second, higher-level sample sizes varied from one study to another $\left(K_{\mathrm{S} 1}=14, K_{\mathrm{S} 2}=\right.$ $\left.41, K_{\mathrm{S} 3}=24, K_{\mathrm{S} 4}=24\right)$. In multilevel modelling, the number of clusters is more important than the number of participants (or than the average number of participants per cluster). For instance, with 30 clusters, standard errors for the second-level variance components are estimated about $15 \%$ too small (see Maas \& Hox, 2005). Although the overall pattern of results speaks in favor of the robustness of performance goals socialization, replications with larger number of level-2 units would be an important future endeavor.

Third, the empirical evidence related to the effect of supervisors' performanceapproach goals on the emergence of subordinates' performance-avoidance goals were 
substantially more complex. In Study 1, unexpected ceiling and floor effects of time were found, whereas in Study 4's, the effect was only found when subordinates (pupils) did not know their supervisors (teachers). These findings might reflect the fact that the socialization of performance-avoidance goals operates rather rapidly, to the extent that, in Study 4, subordinates who knew their performance-approach-oriented supervisors before the study might have already been socialized. Hence, we caution scholars willing to investigate the effect of supervisors' goals on their subordinates' performance-avoidance goals that it might be more difficult to detect.

Fourth, Studies 1 and 2's results did not provide any evidence of mastery goals socialization: Supervisor's mastery goals did not significantly predict subordinates' mastery goals over time. On the one hand, such a null effect might be explained by a perceptual bias. In explaining why cooperation is often (wrongly) perceived as being less prevalent than competition, Kohn (1992) argued that "cooperation is not always plain in the eyes, whereas competition [...] can be readily observed" (p. 22; for an empirical illustration, see Maki, Thorngate, \& McClintock, 1979). As mastery goals rely on a self-referenced standard of competence evaluation, whereas performance-approach goals rely on an other-referenced standard (Elliot, 1999), supervisors' performance-approach goals might be more easily detectable (and endorsed) by subordinates (Eren, 2009). On the other hand, the null effect might be explained by a social desirability bias. Since mastery goals are more socially desirable than performance-approach goals, the level of self-reported mastery goals in the literature is generally inflated relative to that of performance-approach goals (see Darnon et al., 2009). As a matter of fact, in Studies 1 and 2, the distribution of mastery goals was highly skewed to the left, which may have prevented to find evidence of mastery goals socialization. It is therefore not implausible for mastery goals socialization to be observed in social environments in which these goals are not perceived as socially desirable (e.g., organizations 
in which competitiveness is valued and culture is focused on making profit; see Browaeys \& Price, 2008).

Fifth, the present set of studies did not study the mechanism(s) by which supervisors' performance-approach goals are communicated to their subordinates. Drawing on the research on classroom goal structure, it is legitimate to think that supervisors' management and instructional practices could mediate the relationship between supervisors' performanceapproach goals and subordinates' performance-based goals (Ames, 1992). Performanceapproach-oriented supervisors were found to use more repetitive task, to provide more normative feedbacks (Meece, Anderman, \& Anderman, 2005), or to display more transactional leaderships (based on control and monitoring; Hamstra, Van Yperen, Wisse, \& Sassenberg, 2013). These performance-oriented practices may allow subordinates to detect the supervisor's performance-approach goals. Future research might also examine other potential mediators, such as group performance-approach goals (i.e., the desire of the group as an entity to outperform other groups; Porter, 2008) or perceived social utility of performancebased goals (e.g., the perception of performance-approach goals as being an effective tool to succeed; Dompnier et al., 2013).

\subsection{Conclusion}

Scholars have documented various effects pertaining to the hierarchical transmission of values or motives: from caretakers to children (Elliot \& Thrash, 2004), from instructors to trainees (Radel, Sarrazin, Legrain, \& Wild, 2010), or from principals to schoolchildren (Berson \& Oreg, 2016). The present work expands this research by offering a systematic analysis of the phenomenon of performance goals socialization, and providing evidence on its consequences, enabling condition, and directional moderator. Specifically, we have unraveled the role of supervisors, as well as the influence of group-identification and perceived competence, in explaining the evolution of subordinates' performance-based goals. In 
conclusion, the present set of studies sheds a new light on the process of achievement goals construction and shows the critical importance of considering social hierarchy when studying performance goals formation. 


\section{Authors' Note}

We wish to thank Alexandre Crisci, Alex Dionisio Calado, Vincent Reymond, Yannick Sauter, Jeanne Ythier, and Guillaume Bonnaud for their help with data collection. We also wish to thank the principal of the secondary school in which Study 4 was conducted, Martine Giovacchini, Mimon Flandin, who put us in contact with her, and Suzanne Faber, for her help with recruitment of participants. This work was supported by the Swiss National Science Foundation. 


\section{References}

Alwin, D. F., Cohen, R. L., \& Newcomb, T. M. (1991). Political attitudes over the life span: The Bennington women after fifty years. Madison, WI: The University of Wisconsin Press

Ames, C. (1992). Classrooms: Goals, structures, and student motivation. Journal of Educational Psychology, 84, 261-271.

Anderman, L. H., \& Anderman, E. M. (1999). Social predictors of changes in students' achievement goal orientations. Contemporary Educational Psychology, 24, 21-37.

Bacharach, S. B., Bamberger, P., \& Conley, S. (1991). Work-home conflict among nurses and engineers: Mediating the impact of role stress on burnout and satisfaction at work. Journal of Organizational Behavior, 12, 39-53.

Bachman, J. G., Sigelman, L., \& Diamond, G. (1987). Self-selection, socialization, and distinctive military values: Attitudes of high school seniors. Armed Forces \& Society, $13,169-187$.

Barić, R. (2007). The relationship of coach's leadership behaviour and his motivational structure with athletes' motivational tendencies (Unpublished doctoral dissertation). University of Ljubljana, Ljubljana, Slovenia.

Bender, G. J. (1967). Political socialization and political change. The Western Political Quarterly, 20, 390-407.

Berson, Y., \& Oreg, S. (2016). The Role of School Principals in Shaping Children's Values. Psychological Science. In press.

Berk, K., \& Carey, P. (2009). Data analysis with Microsoft Excel: Updated for Office 2007. Cengage Learning. 
Bigot, J., Pichot, N., \& Testé, B. (2004). Is there a drop in normative clearsightedness in sixth grade? Study of internality and normative clearsightedness in fourth to seventh graders. European Journal of Psychology of Education, 19, 335-347.

Boardley, I. D., \& Kavussanu, M. (2010). Effects of goal orientation and perceived value of toughness on antisocial behavior in soccer: The mediating role of moral disengagement. Journal of Sport and Exercise Psychology, 32, 176-192.

Browaeys, M.-J., \& Price, R. (2008). Understanding cross-cultural management. Harlow, UK: Pearson Education.

Butler, R. (2007). Teachers' achievement goal orientations and associations with teachers' help seeking: Examination of a novel approach to teacher motivation. Journal of Educational Psychology, 99, 241-252.

Cammann, C., Fichman, M., Jenkins, G. D., \& Klesh, J. (1983). Michigan organizational assessment questionnaire. In S. E. Seashore, E. E. Lawler, P. H. Mirvis, \& C. Cammann (Eds.), Assessing organizational change: A guide to methods, measures, and practices (pp. 71-138). New York: Wiley.

Church, M. A., Elliot, A. J., \& Gable, S. L. (2001). Perceptions of classroom environment, achievement goals, and achievement outcomes. Journal of Educational Psychology, 93, 43-54.

Corker, K. S., Donnellan, M. B., \& Bowles, R. P. (2013). The development of achievement goals throughout college modeling stability and change. Personality and Social Psychology Bulletin, 39, 1404-1417.

Darnon, B., \& Butera, F. (2005). Buts d'accomplissement, stratégies d'étude, et motivation intrinsèque: présentation d'un domaine de recherche et validation française de l'échelle d'Elliot et McGregor (2001) [Achievement goals, study strategies, and intrinsic 
motivation: Presenting a domain of research and the French validation of Elliot \& McGregor's scale]. L'Année Psychologique, 105, 105-131.

Darnon, C., Dompnier, B., Delmas, F., Pulfrey, C., \& Butera, F. (2009). Achievement goal promotion at university: social desirability and social utility of mastery and performance goals. Journal of Personality and Social Psychology, 96, 119-134.

Darnon, C., Dompnier, B., \& Poortvliet, M. P. (2012). Achievement goals in educational contexts: A social psychology perspective. Social and Personality Psychology Compass, 6, 760-771.

Darnon, C., Harackiewicz, J. M., Butera, F., Mugny, G., \& Quiamzade, A. (2007). Performance-approach and performance-avoidance goals: When uncertainty makes a difference. Personality and Social Psychology Bulletin, 33, 813-827.

Dierdorff, E. C., \& Ellington, J. K. (2012). Members Matter in Team Training: Multilevel and Longitudinal Relationships Between Goal Orientation, Self-Regulation, and Team Outcomes. Personnel Psychology, 65, 661-703.

Diseth, A., \& Samdal, O. (2014). Autonomy support and achievement goals as predictors of perceived school performance and life satisfaction in the transition between lower and upper secondary school. Social Psychology of Education, 1-23.

Doise, W. (1986). Levels of explanation in social psychology. Cambridge, UK: Cambridge University Press.

Dompnier, B., Darnon, C., \& Butera, F. (2009). Faking the desire to learn: A clarification of the link between mastery goals and academic achievement. Psychological Science, 20, 939-943.

Dompnier, B., Darnon, C., \& Butera, F. (2013). When performance-approach goals predict academic achievement and when they do not: A social value approach. British Journal of Social Psychology, 52, 587-596. 
Dompnier, B., Darnon, C., Delmas, F., \& Butera, F. (2008). Achievement goals and social judgment: The performance-approach goals paradox. International Review of Social Psychology / Revue Internationale de Psychologie Sociale, 21, 247-271.

Dragoni, L. (2005). Understanding the emergence of state goal orientation in organizational work groups: the role of leadership and multilevel climate perceptions. Journal of Applied Psychology, 90, 1084-1095.

Dweck, C. S. (1986). Motivational processes affecting learning. American Psychologist, 41, 1040-1048.

Elliot, A. J. (1999). Approach and avoidance motivation and achievement goals. Educational Psychologist, 34, 169-189.

Elliot, A. J., \& Church, M. A. (1997). A hierarchical model of approach and avoidance achievement motivation. Journal of Personality and Social Psychology, 72, 218-232.

Elliot, A. J., \& McGregor, H. A. (2001). A 2*2 achievement goal framework. Journal of Personality and Social Psychology, 80, 501-519.

Elliot, A. J., McGregor, H. A., \& Gable, S. L. (1999). Achievement goals, study strategies, and exam performance: A mediational analysis. Journal of Educational Psychology, $91,549-563$.

Elliot, A. J., Murayama, K., \& Pekrun, R. (2011). A $3 \times 2$ achievement goal model. Journal of Educational Psychology, 103, 632.

Elliot, A. J., \& Thrash, T. M. (2002). Approach-avoidance motivation in personality: approach and avoidance temperaments and goals. Journal of Personality and Social Psychology, 82, 804-818.

Eren, A. (2009). Exploring the relationships among mirror neurons, theory of mind, and achievement goals: Towards a model of achievement goal contagion in educational settings. Educational Research Review, 4, 233-247. 
Falomir-Pichastor, J. M., Mugny, G., Invernizzi, F., Di Palma, A., \& Estrada, M. M. (2007). Does the campaign against tobacco use necessarily reduce the attractions of smoking for young people? Identity issues surrounding initiation into tobacco consumption. Revue Européenne de Psychologie Appliquée / European Review of Applied Psychology, 57, 257-265.

Franklin, D. A., Porter, C. O., \& Swider, B. W. (2013). The interactive effects of team content goals and leader goal orientation. In Academy of Management Proceedings (Vol. 2013, No. 1, p. 10671). Academy of Management.

Feldman, D. C. (1994). Who's socializing whom? The impact of socializing newcomers on insiders, work groups, and organizations. Human Resource Management Review, 4, 213-233.

Fidell, L. S., \& Tabachnick. B. G. (2003). Preparatory data analysis. In J. A. Schinka \& W. F. Velicer (Eds.), Handbook of psychology (Vol. 2, pp. 115-121). New York: Wiley.

Fryer, J. W., \& Elliot, A. J. (2007). Stability and change in achievement goals. Journal of Educational Psychology, 99, 700-714.

Galinsky, A. D., Magee, J. C., Gruenfeld, D. H., Whitson, J. A., \& Liljenquist, K. A. (2008). Power reduces the press of the situation: implications for creativity, conformity, and dissonance. Journal of Personality and Social Psychology, 95, 1450-1466.

Gatto, J., Dambrun, M., Kerbrat, C., \& De Oliveira, P. (2010). Prejudice in the police: On the processes underlying the effects of selection and group socialisation. European Journal of Social Psychology, 40, 252-269.

Grehaigne, J. F., Godbout, P., \& Bouthier, D. (1997). Performance assessment in team sports. Journal of Teaching in Physical Education, 16, 500-516. 
Grojean, M. W., Resick, C. J., Dickson, M. W., \& Smith, D. B. (2004). Leaders, values, and organizational climate: Examining leadership strategies for establishing an organizational climate regarding ethics. Journal of Business Ethics, 55, 223-241.

Guimond, S. (2000). Group socialization and prejudice: The social transmission of intergroup attitudes and beliefs. European Journal of Social Psychology, 30, 335-354.

Guinote, A. (2007). Power and goal pursuit. Personality and Social Psychology Bulletin, 33, 1076-1087.

Gully, S. M., \& Phillips, J. M. (2005). A multilevel application of learning and performance orientations to individual, group, and organizational outcomes. Research in Personnel and Human Resources Management, 24, 1-51.

Halvari, H., \& Kjormo, O. (1999). A structural model of achievement motives, performance approach and avoidance goals, and performance among Norwegian Olympic athletes. Perceptual and Motor Skills, 89, 997-1022.

Harackiewicz, J. M., Barron, K. E., Tauer, J. M., \& Elliot, A. J. (2002). Predicting success in college: A longitudinal study of achievement goals and ability measures as predictors of interest and performance from freshman year through graduation. Journal of Educational Psychology, 94, 562-575.

Harackiewicz, J. M., \& Linnenbrink, E. A. (2005). Multiple achievement goals and multiple pathways for learning: The agenda and impact of Paul R. Pintrich. Educational Psychologist, 40, 75-84.

Hamstra, M. R., Van Yperen, N. W., Wisse, B., \& Sassenberg, K. (2013). Transformational and transactional leadership and followers' achievement goals. Journal of Business and Psychology, 3, 413-425.

Hendricks, J. W., \& Payne, S. C. (2007). Beyond the Big Five: Leader goal orientation as a predictor of leadership effectiveness. Human Performance, 20, 317-343. 
Hirsch, J. E. (2005). An index to quantify an individual's scientific research output. Proceedings of the National academy of Sciences of the United States of America, 102, 16569-16572.

Hornsey, M. J. (2008). Social identity theory and self- categorization theory: A historical review. Social and Personality Psychology Compass, 2, 204-222.

Jagacinski, C. M., Kumar, S., Boe, J. L., Lam, H., \& Miller, S. A. (2010). Changes in achievement goals and competence perceptions across the college semester. Motivation and Emotion, 34, 191-204.

Janssen, O. (2000). Job demands, perceptions of effort-reward fairness and innovative work behaviour. Journal of Occupational and Organizational Psychology, 73, 287-302.

Janssen, O., \& Van Yperen, N. W. (2004). Employees' goal orientations, the quality of leadermember exchange, and the outcomes of job performance and job satisfaction. Academy of Management Journal, 47, 368-384.

Judd, C. M., Yzerbyt, V. Y., \& Muller, D. (2014). Mediation and moderation. In H. T. Reis \& C. M. Judd (Eds.), Handbook of research methods in social and personality psychology (2nd edition, pp. 653-676). Cambridge, UK: Cambridge University Press.

Kaplan, A., \& Flum, H. (2010). Achievement goal orientations and identity formation styles. Educational Research Review, 5, 50-67.

Kasser, T., Cohn, S., Kanner, A. D., \& Ryan, R. M. (2007). Some costs of American corporate capitalism: A psychological exploration of value and goal conflicts. Psychological Inquiry, 18, 1-22.

Kavussanu, M. (2006). Motivational predictors of prosocial and antisocial behaviour in football. Journal of Sports Sciences, 24, 575-588.

Keltner, D., Gruenfeld, D. H., \& Anderson, C. (2003). Power, approach, and inhibition. Psychological Review, 110, 265-284. 
Kohn, A. (1992). No contest: The case against competition (Revised Edition). Boston, MA: Houghton Mills.

Kumar, S., \& Jagacinski, C. M. (2011). Confronting task difficulty in ego involvement: Change in performance goals. Journal of Educational Psychology, 103, 664-682.

Law, W., Elliot, A. J., \& Murayama, K. (2012). Perceived competence moderates the relation between performance-approach and performance-avoidance goals. Journal of Educational Psychology, 104, 806-819.

LePine, J. A. (2005). Adaptation of teams in response to unforeseen change: effects of goal difficulty and team composition in terms of cognitive ability and goal orientation. Journal of Applied Psychology, 90, 1153-1167.

Maas, C. J., \& Hox, J. J. (2005). Sufficient sample sizes for multilevel modeling. Methodology: European Journal of Research Methods for the Behavioral and Social Sciences, 1, 86-92.

MacKinnon, D. P., Lockwood, C. M., \& Williams, J. (2004). Confidence limits for the indirect effect: Distribution of the product and resampling methods. Multivariate Behavioral Research, 39, 99-128.

Maki, J. E., Thorngate, W. B., \& McClintock, C. G. (1979). Prediction and perception of social motives. Journal of Personality and Social Psychology, 37, 203-220.

Martin, R., \& Epitropaki, O. (2001). Role of organizational identification on implicit leadership theories (ILTs), transformational leadership and work attitudes. Group Processes \& Intergroup Relations, 4, 247-262.

McAuliffe, B. J., Jetten, J., Hornsey, M. J., \& Hogg, M. A. (2003). Individualist and collectivist norms: When it's ok to go your own way. European Journal of Social Psychology, 33, 57-70. 
Meece, J. L., Anderman, E. M., \& Anderman, L. H. (2006). Classroom goal structure, student motivation, and academic achievement. Annual Review of Psychology, 57, 487-503.

Meece, J. L., \& Miller, S. D. (2001). A longitudinal analysis of elementary school students' achievement goals in literacy activities. Contemporary Educational Psychology, 26, 454-480.

Michel, J. W., Wallace, D. L., \& Rawlings, R. A. (2013). Charismatic leaders: the role of admiration and system justification. Leadership \& Organization Development Journal, $34,469-487$.

Moreland, R. L, \& Levine J. M. (1982). Socialization in small groups: Temporal changes in individual-group relations. In, L. Berkowitz (Ed.), Advances in experimental social psychology (Vol. 15, pp. 137-192). New York, NY: Academic Press.

Muis, K. R., \& Edwards, O. (2009). Examining the stability of achievement goal orientation. Contemporary Educational Psychology, 34, 265-277.

Murdock, T. B., \& Anderman, E. M. (2006). Motivational perspectives on student cheating: Toward an integrated model of academic dishonesty. Educational Psychologist, 41, 129-145.

Murayama, K., \& Elliot, A. J. (2011). Achievement motivation and memory achievement goals differentially influence immediate and delayed remember-know recognition memory. Personality and Social Psychology Bulletin, 37, 1339-1348.

Murayama, K., \& Elliot, A. J. (2012a). The competition-performance relation: A metaanalytic review and test of the opposing processes model of competition and performance. Psychological Bulletin, 138, 1035-1070.

Murayama, K., \& Elliot, A. J. (2012b). Further clarifying the competition-performance relation: Reply to DW Johnson et al.(2012). Psychological Bulletin, 138, 1079-1084. 
Murayama, K., Elliot, A. J., \& Yamagata, S. (2011). Separation of performance-approach and performance-avoidance achievement goals: A broader analysis. Journal of Educational Psychology, 103, 238-256.

Newcomb, T. M. (1943). Personality and social change. New York: Dryden Press.

Newcomb, T. L., Koenig, K. E., Flacks, R., \& Warwick, D. P. (1967). Persistence and change: Bennington College and its students after 25 years. New York: John Wiley and Sons.

Papaioannou, A., Bebetsos, E., Theodorakis, Y., Christodoulidis, T., \& Kouli, O. (2006). Causal relationships of sport and exercise involvement with goal orientations, perceived competence and intrinsic motivation in physical education: A longitudinal study. Journal of Sports Sciences, 24, 367-382.

Patrick, H., Kaplan, A., \& Ryan, A. M. (2011). Positive classroom motivational environments: Convergence between mastery goal structure and classroom social climate. Journal of Educational Psychology, 103, 367-382.

Pekrun, R., Elliot, A. J., \& Maier, M. A. (2009). Achievement goals and achievement emotions: Testing a model of their joint relations with academic performance. Journal of Educational Psychology, 101, 115-135.

Poortvliet, P. M., \& Darnon, C. (2010). Toward a more social understanding of achievement goals: The interpersonal effects of mastery and performance goals. Current Directions in Psychological Science, 19, 324-328.

Poortvliet, P. M., \& Giebels, E. (2012). Self-improvement and cooperation: How exchange relationships promote mastery-approach driven individuals' job outcomes. European Journal of Work and Organizational Psychology, 21, 392-425.

Porter, C. O. L. H. (2008). A multilevel, multiconceptualization perspective of goal orientation in teams. In V. I. Sessa \& M. London (Eds.), Work group learning: 
Understanding and assessing how groups learn in organizations (pp. 149-173). New York, NY: Taylor \& Francis.

Preacher, K. J., \& Selig, J. P. (2012). Advantages of Monte Carlo confidence intervals for indirect effects. Communication Methods and Measures, 6, 77-98.

Preenen, P. T., Van Vianen, A. E., \& De Pater, I. E. (2014). Challenging assignments and activating mood: The influence of goal orientation. Journal of Applied Social Psychology, 44, 650-659.

Radel, R., Sarrazin, P., Legrain, P., \& Wild, T. C. (2010). Social contagion of motivation between teacher and student: Analyzing underlying processes. Journal of Educational Psychology, 102, 577-587.

Retelsdorf, J., \& Günther, C. (2011). Achievement goals for teaching and teachers' reference norms: Relations with instructional practices. Teaching and Teacher Education, 27, 1111-1119.

Rucker, D. D., Preacher, K. J., Tormala, Z. L., \& Petty, R. E. (2011). Mediation analysis in social psychology: Current practices and new recommendations. Social and Personality Psychology Compass, 5, 359-371.

Rumberger, R. W. (2001). Why students drop out of high school and what can be done. Paper prepared for the conference, "Dropouts in America: How Severe is the Problem? What Do We Know about Intervention and Prevention?" Cambridge, Massachusetts: Harvard University. Retrieved from: http://civilrightsproject.ucla.edu/research/k-12education/school-dropouts/why-students-drop-out-of-school-and-what-can-bedone/rumberger-why-students-dropout-2001.pdf

Ryan, R. M., Rigby, C. S., \& Przybylski, A. (2006). The motivational pull of video games: A self-determination theory approach. Motivation and Emotion, 30, 344-360. 
Sage, L., Kavussanu, M., \& Duda, J. (2006). Goal orientations and moral identity as predictors of prosocial and antisocial functioning in male association football players. Journal of Sports Sciences, 24, 455-466.

Sarrazin, P., Vallerand, R., Guillet, E., Pelletier, L., \& Cury, F. (2002). Motivation and dropout in female handballers: A 21-month prospective study. European Journal of Social Psychology, 32, 395-418.

Schwartz, S. H., Melech, G., Lehmann, A., Burgess, S., Harris, M., \& Owens, V. (2001). Extending the cross-cultural validity of the theory of basic human values with a different method of measurement. Journal of Cross-Cultural Psychology, 32, 519-542.

Senko, C., \& Harackiewicz, J. M. (2005). Regulation of Achievement Goals: The Role of Competence Feedback. Journal of Educational Psychology, 97, 320-336.

Senko, C., Hulleman, C. S., \& Harackiewicz, J. M. (2011). Achievement goal theory at the crossroads: Old controversies, current challenges, and new directions. Educational Psychologist, 46, 26-47.

Shim, S. S., Ryan, A. M., \& Anderson, C. J. (2008). Achievement goals and achievement during early adolescence: Examining time-varying predictor and outcome variables in growth-curve analysis. Journal of Educational Psychology, 100, 655-671.

Skaalvik, E. M., \& Skaalvik, S. (2013). Teachers' perceptions of the school goal structure: Relations with teachers' goal orientations, work engagement, and job satisfaction. International Journal of Educational Research, 62, 199-209.

Slabu, L., \& Guinote, A. (2010). Getting what you want: Power increases the accessibility of active goals. Journal of Experimental Social Psychology, 46, 344-349.

Smith, P. K., \& Bargh, J. A. (2008). Nonconscious effects of power on basic approach and avoidance tendencies. Social Cognition, 26, 1-24. 
Sommet, N., Darnon C., \& Butera, F. (2015). To confirm or to conform? Performance goals as a regulator of conflict with more-competent others. Journal of Educational Psychology, 107, 580-598.

Sommet, N., Darnon, C., Mugny, G., Quiamzade, A., Pulfrey, C., Dompnier, B., \& Butera, F. (2014). Performance goals in conflictual social interactions: Towards the distinction between two modes of relational conflict regulation. British Journal of Social Psychology, 53, 134-153.

Steinfeldt, J. A., Foltz, B. D., Mungro, J., Speight, Q. L., Wong, Y. J., \& Blumberg, J. (2011). Masculinity socialization in sports: Influence of college football coaches. Psychology of Men \& Masculinity, 12, 247-259.

Stephens, D. E. (2000). Predictors of likelihood to aggress in youth soccer: An examination of coed and all-girls teams. Journal of Sport Behavior, 23, 311-325.

Stoeber, J., Stoll, O., Pescheck, E., \& Otto, K. (2008). Perfectionism and achievement goals in athletes: Relations with approach and avoidance orientations in mastery and performance goals. Psychology of Sport and Exercise, 9, 102-121.

Tanaka, A., Okuno, T., \& Yamauchi, H. (2013). Longitudinal tests on the influence of achievement goals on effort and intrinsic interest in the workplace. Motivation and Emotion, 37, 457-464.

Treasure, D. C., \& Robert, G. C. (2001). Students' perceptions of the motivational climate, achievement beliefs, and satisfaction in physical education. Research Quarterly for Exercise and Sport, 72, 165-175.

Tuominen-Soini, H., Salmela-Aro, K., \& Niemivirta, M. (2012). Achievement goal orientations and academic well-being across the transition to upper secondary education. Learning and Individual Differences, 22, 290-305. 
Terry, D. J., \& Hogg, M. A. (1996). Group norms and the attitude-behavior relationship: A role for group identification. Personality and Social Psychology Bulletin, 22, 776-793.

Turner, J. C., Hogg, M. A., Oakes, P. J., Reicher, S. D., \& Wetherell, M. S. (1987).

Rediscovering the social group: A self-categorization theory. Basil Blackwell.

Tyler, T. (2006). Psychological perspectives on legitimacy and legitimation. Annual Review of Psychology, 57, 375-400.

Urdan, T., \& Schoenfelder, E. (2006). Classroom effects on student motivation: Goal structures, social relationships, and competence beliefs. Journal of School Psychology, $44,331-349$.

Valentiner, D. P., Mounts, N. S., Durik, A. M., \& Gier-Lonsway, S. L. (2011). Shyness mindset: Applying mindset theory to the domain of inhibited social behavior. Personality and Individual Differences, 50, 1174-1179.

VandeWalle, D., Brown, S. P., Cron, W. L., \& Slocum Jr, J. W. (1999). The influence of goal orientation and self-regulation tactics on sales performance: A longitudinal field test. Journal of Applied Psychology, 84, 249-259.

Van Yperen, N. (2003). The perceived profile of goal orientation within firms: Differences between employees working for successful and unsuccessful firms employing either performance-based pay or job-based pay. European Journal of Work and Organizational Psychology, 12, 229-243.

Wenzel, M. (2004). The social side of sanctions: personal and social norms as moderators of deterrence. Law and Human Behavior, 28, 547-567.

Willis, G. B., \& Guinote, A. (2011). The effects of social power on goal content and goal striving: A situated perspective. Social and Personality Psychology Compass, 5, 706719. 
Wolters, C. A. (2004). Advancing achievement goal theory: Using goal structures and goal orientations to predict students' motivation, cognition, and achievement. Journal of Educational Psychology, 96, 236-250.

Wolters, C. A., Fan, W., \& Daugherty, S. (2010). Teacher-reported goal structures: Assessing factor structure and invariance. The Journal of Experimental Education, 79, 1-29. 


\section{Footnotes}

${ }^{1}$ Following generations of achievement goals research have additionally differentiated mastery goals in terms of valence (i.e., mastery-approach vs. mastery-avoidance goals; a $2 \mathrm{x}$ 2 framework, Elliot \& McGregor, 2001) and in terms of standard for evaluating selfcompetence (i.e., task- vs. self-goals; a 3 x 2 framework, Elliot, Murayama, \& Pekrun, 2011). As in this research we mostly focus on performance goals, we do not get into the details of these various distinctions.

${ }^{2}$ For exploratory purposes, we distinguished performance-approach goals toward outgroup members (i.e., desire to outperform opponents; as described above) from performanceapproach goals (i.e., desire to outperform teammates; 3 items, e.g., "When I play soccer, it is important for me to play better than the players of my teams"; $\alpha=.83, M=4.60, S D=1.57$ ). The former corresponds to performance-approach goals as classically conceptualized in achievement goals research in sport (see for instance, Sage, Kavussanu and Duda, 2006). The latter form — to the best of our knowledge — has not been clearly conceptualized in the literature. Neither coaches' performance-approach, $B=-0.04[-0.33,0.25], Z<|1|, p=.806$, not the interaction between coaches' performance-approach and time, $B=-0.01[-0.05,0.02]$, $Z<|1|, p=.546$, were significantly different from zero. Thus, this variable was not further considered in the present manuscript.

${ }^{3}$ The fact that the standard deviation of the variable was superior to its mean indicated a large dispersion of individual responses. Specifically, data showed a highly right-skewed distribution $(s k=2.99)$ increasing the likelihood of outlier(s) being present. Using the interquarile method, with a conservative cut-off of $Q_{1}-3 * I Q R<x_{i}<Q_{3}+3 * I Q R$ (where $Q_{1}$ is the first quartile, $Q_{3}$ the third one, and $I Q R$ the interquartile range; see Berk \& Carey, 2009), we detected six potential influential observations. However, as excluding them did not 
change the patterns of results all hypothesized interaction effects remained significant at $p$ $<.01)$, they were retained for the reported analyses.

${ }^{4}$ Thereafter the ", $95 \% \mathrm{CI}$ ” is omitted. All square brackets therefore indicate a $95 \%$ confidence interval.

${ }^{5}$ We conducted a series of preliminary diagnostic analysis in order to detect potential influential observations. DFFITS values — providing a measure of how deleting a particular observation modifies regression results - were calculated. For one observation, they were found to be above the cutoff point (i.e., $\mid$ DFFITS $\mid>2 * \sqrt{ }(k / n)$, where $k$ is the number of regressors, and $n$ the number of observations; Fidell \& Tabachnick, 2003) for both performance-approach and -avoidance goals. Respective DFFITS values were of .41 and .43. In keeping the participant, the interaction effects hypothesized in 1a and $1 \mathrm{~b}$ remained significant $(p s<.045)$. In removing it, they became clearer $(p s<.026)$.

${ }^{6}$ For mastery goals, the low alpha value results from the low variance in participant responses (n.b., less than $8 \%$ of the items responses were different than 6 or 7 ; for a similar problem, see Darnon, Dompnier, Delmas, Pulfrey, \& Butera, 2009).

${ }^{7}$ Given the exploratory nature of the present study, two additional variables were measured: (i) Seven items assessed the quality of leader-member exchange (e.g., "My working relationship with my thesis supervisor is effective"; $\alpha=.93, M=5.63, S D=1.22$; Janssen \& Van Yperen, 2004); (ii) Nine items assessed creativity "How often do you create new ideas for improvement in your work?”; $\alpha=.88, M=3.68, S D=0.94$; Janssen, 2000). However, as the interaction effects between time students spent with their supervisors and thesis supervisors' performance-approach goals on both of these outcomes were nonsignificant, detailed results were neither presented nor discussed.

${ }^{8}$ Interactions between the potential achievement goal mediators were taken into account in order to increase the predictive accuracy of our model. Past research controlled this 
kind of achievement goal interactions when using satisfaction- or drop out-related measures as outcomes (e.g., Janssen \& Van Yperen, 2004). However, the moderation effects were not reported in the main manuscript since the focus was not on the issue of multiple goals (for a literature review on this matter, see Harackiewicz, \& Linnenbrink, 2005). It is worth noting that analysis revealed an interaction between $\mathrm{Ph} . \mathrm{D}$ students' mastery and performanceapproach goals on both satisfaction, $B=0.49[0.17,0.80], Z=3.06, p=.002$, and intention to drop out, $B=-0.66[-0.98,-0.33], Z=-3.97, p<.001$. No other interaction effect reached significance. The details of the results are presented in Supplementary Material (Table S3).

${ }^{9}$ In the context of multiple mediators (i.e., here Ph.D students' achievement goals), the reduction of total effect-i.e., the total effect $(c)$ minus the direct effect $\left(c^{\prime}\right)$ - has poor diagnostic value. Indeed, mediator variables can interfere with each other (e.g., one of it can work as a suppressor variable, Judd, Muller, \& Yzerbit, 2014) and, accordingly, Rucker, Preacher, Tormala and Petty (2011) recommend to "abandon the emphasis on the significance of c and c' [in conducting mediation analyses]"' (p. 368).

${ }^{10}$ Confidence intervals were construed using the Monte Carlo simulation (MC;) rather than the bias-corrected bootstrap method, as Preacher and Selig (2012) demonstrated that "until one bootstrap method emerges as best in the multilevel context, MC may be the only viable method [to assess indirect effect]" (p. 94).

${ }^{11}$ Two elements have to be made clear. First, one team had two Clan Officers. Performance-approach goals of these two leaders were therefore averaged. Second, eight teams had no Clan Officer. For these teams, we treated their Clan Leader (i.e., the highest remaining rank) as being the leader. In assessing the (potential) consequences of such a decision, we entered this variable in our final model (coded "- 0.5 " for members having a "Clan Leader" as a leader and " +0.5 " for the ones having a "Clan Officer" as a leader). As the variable neither produced significant effect on team-members' performance-approach ( $p$ 
$=.427)$ and -avoidance $(p=.806)$, nor changed the pattern of the expected second-order interaction, the distinction was not further considered.

${ }^{12}$ For the sake of full disclosure, teachers also answered six items extracted from the Portrait Values Questionnaire (Schwartz et al., 2001); the analysis of these materials is not reported, as they do not inform the present set of hypotheses.

${ }^{13}$ The conclusions of the main analysis are the same when using pupils' performance goals at Wave 2 as the outcome variable (while controlling for performance-approach and avoidance goals at Wave 1). In doing so, the interaction effect between teachers' performance-approach goals and pupils' perceived self-competence on pupils' performance goals at Wave 2 is $B=0.02$ [0.01, 0.04], $Z=3.19, p<.001$, whereas the second-order interaction between teachers' performance-approach goals, pupils' perceived self-competence, and teacher familiarity on pupils' performance-avoidance goal at Wave 2 is $B=0.03[0.01$, $0.06], Z=2.36, p=.018$. However, we have decided to keep using the difference score as the outcome variable because this enabled us to estimate the average change in goal endorsement. 
Table 1.

Coefficient estimates and confidence intervals for the models testing the effects of coaches' performance-approach goals and time on players' achievement goals (Study 1).

\begin{tabular}{|c|c|c|c|c|c|c|c|}
\hline & & \multicolumn{2}{|c|}{$\begin{array}{c}\text { Players' } \\
\text { mastery goals }\end{array}$} & \multicolumn{2}{|c|}{$\begin{array}{l}\text { Players' performance- } \\
\text { approach goals }\end{array}$} & \multicolumn{2}{|c|}{$\begin{array}{c}\text { Players' performance- } \\
\text { avoidance goals }\end{array}$} \\
\hline & & $B$ & $\mathrm{CI}$ & $B$ & $\mathrm{CI}$ & $B$ & $\mathrm{CI}$ \\
\hline \multirow{2}{*}{ Level 1} & Time spent in the team - linear $\left(\mathrm{Tl}_{\mathrm{ij}}\right), B_{10}$ & -0.04 & {$[-0.14,0.06]$} & 0.00 & {$[-0.06,0.06]$} & -0.02 & {$[-0.14,0.11]$} \\
\hline & Time spent in the team - quadratic $\left(\mathrm{Tq}_{\mathrm{ij}}\right), B_{20}$ & - & - & - & - & 0.01 & {$[-0.01,0.02]$} \\
\hline \multirow[t]{2}{*}{ Cross-level } & Linear time x performance-approach goals, $B_{11}$ & -0.04 & {$[-0.10,0.03]$} & $0.07 * * *$ & {$[0.03,0.11]$} & $0.07 *$ & {$[0.01,0.13]$} \\
\hline & Quadratic time x performance-approach goals, $B_{12}$ & - & - & - & - & $-0.03 * * *$ & {$[-0.04,-0.01]$} \\
\hline \multirow[t]{2}{*}{ Residual } & Level-1 error, $\operatorname{var}\left(e_{\mathrm{ij}}\right)$ & 1.19 & & 0.08 & & 0.60 & \\
\hline & Level-2 error, $\operatorname{var}\left(u_{0 \mathrm{j}}\right)$ & 0.47 & & 1.48 & & 1.21 & \\
\hline
\end{tabular}

Note: The equation of the cross-level interaction model is $\mathrm{Y}_{\mathrm{ij}}=B_{00}+B_{10} * \mathrm{Tl}_{\mathrm{ij}}+B_{20} * \mathrm{Tq}_{\mathrm{ij}}+B_{01} * \mathrm{SPAp}_{\mathrm{j}}+B_{11} * \mathrm{Tl}_{\mathrm{ij}} * \mathrm{SPAp}_{\mathrm{j}}+B_{12} * \mathrm{Tq}_{\mathrm{ij}} * \mathrm{SPAp}_{\mathrm{j}}$ $+u_{0 \mathrm{j}}+\mathrm{e}_{\mathrm{ij}}$; ${ }^{* * *} p<.01,{ }^{*} p<.05$. 
Table 2.

Coefficient estimates and confidence intervals for the models testing the effects of thesis supervisors' performance-approach goals and time on players' achievement goals (Study 2).

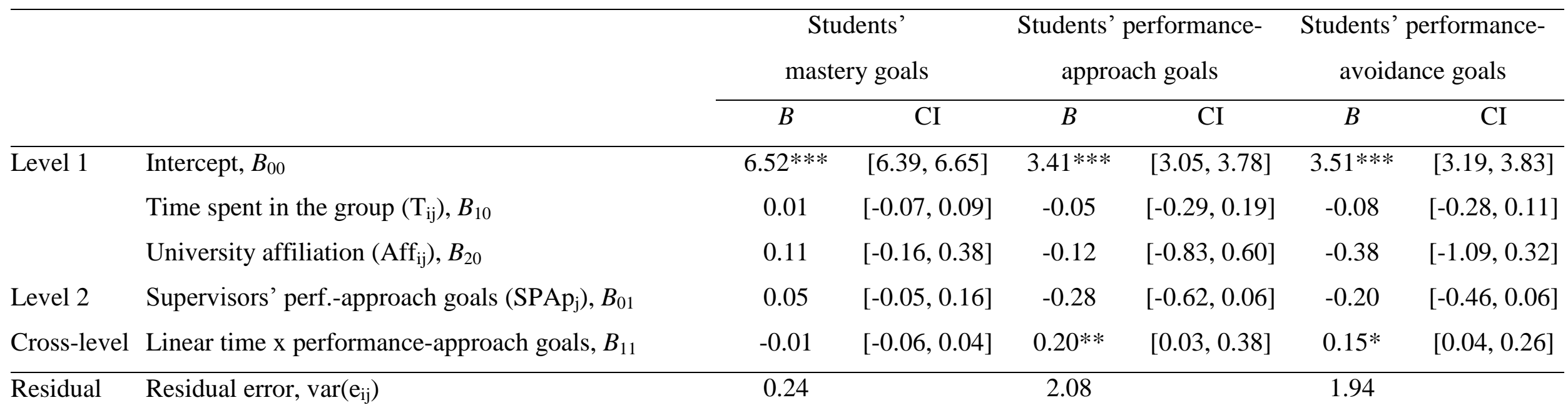

Note: The equation of the maximum likelihood regression model with standard errors adjusted for clustering is $\mathrm{Y}_{\mathrm{ij}}=B_{00}+B_{10} * \mathrm{~T}_{\mathrm{ij}}+B_{20} * \mathrm{Aff}_{\mathrm{ij}}+$ $B_{01} * \mathrm{SPAp}_{\mathrm{j}}+B_{11} * \mathrm{Tl}_{\mathrm{ij}} * \mathrm{SPAp}_{\mathrm{j}}+e_{\mathrm{ij}} ; * * * p<.01, * * p<.01, * p<.05$. 
Table 3.

Coefficient estimates and confidence intervals for the models testing the effects of thesis supervisors' performance-approach goals and time on drop out and satisfaction, as mediated by students' achievement goals (Study 2).

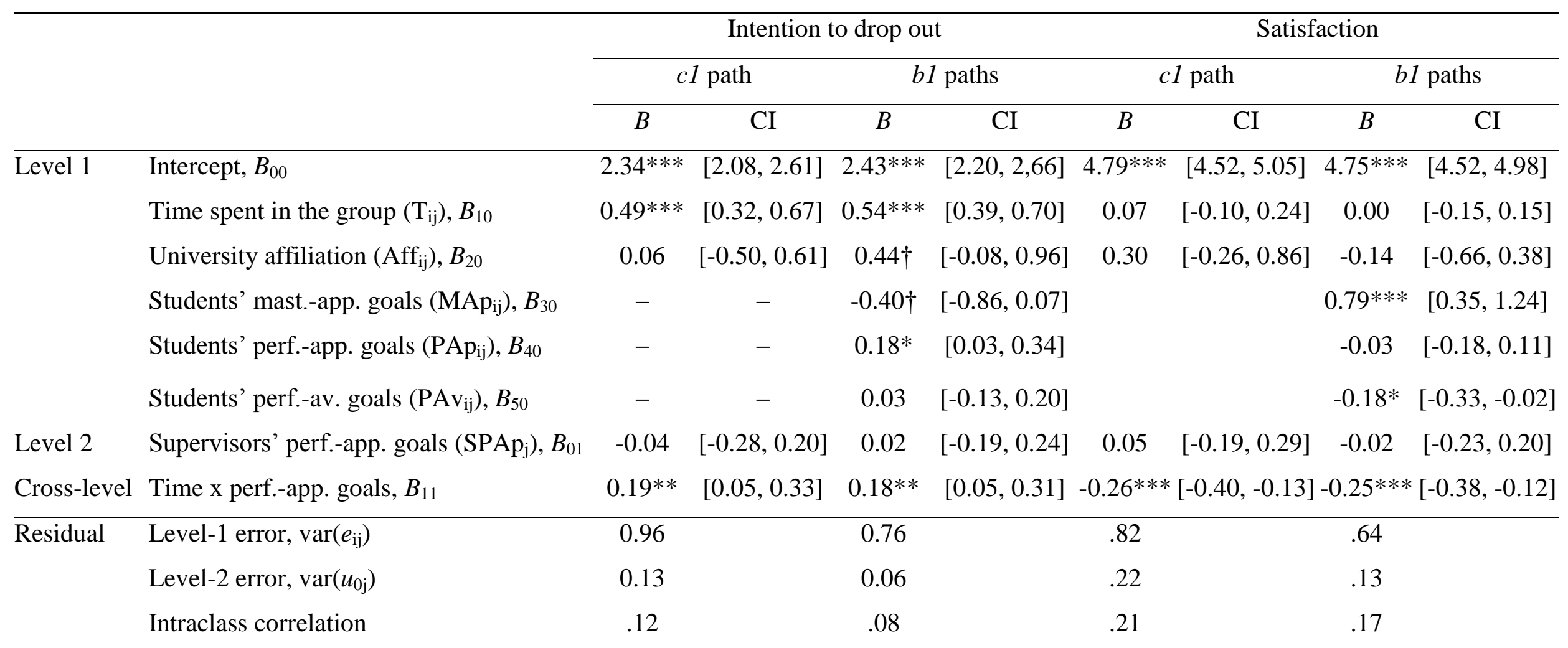

Notes: The equation of the cross-level interaction model is $\mathrm{Y}_{\mathrm{ij}}=B_{00}+B_{10} * \mathrm{~T}_{\mathrm{ij}}+B_{20} * \mathrm{Aff}_{\mathrm{ij}}+B_{30} * \mathrm{MAp}_{\mathrm{ij}}+B_{40} * \mathrm{PAp}_{\mathrm{ij}}+B_{50} * \mathrm{PAv}_{\mathrm{ij}}+B_{01} *$ $\mathrm{SPAp}_{\mathrm{j}}+B_{11} * \mathrm{Tl}_{\mathrm{ij}} * \mathrm{SPAp}_{\mathrm{j}}+u_{0 \mathrm{j}}+e_{\mathrm{ij}}$ ) ; The interaction effects between Ph.D. goals are not reported; *** $p<.001, * * p<.01, * p<.05, \dagger p<.1$. 
Table 4.

Coefficient estimates and confidence intervals for the models testing the effects of leaders' performance-approach goal, time, and identification on players' performance goals (Study 3).

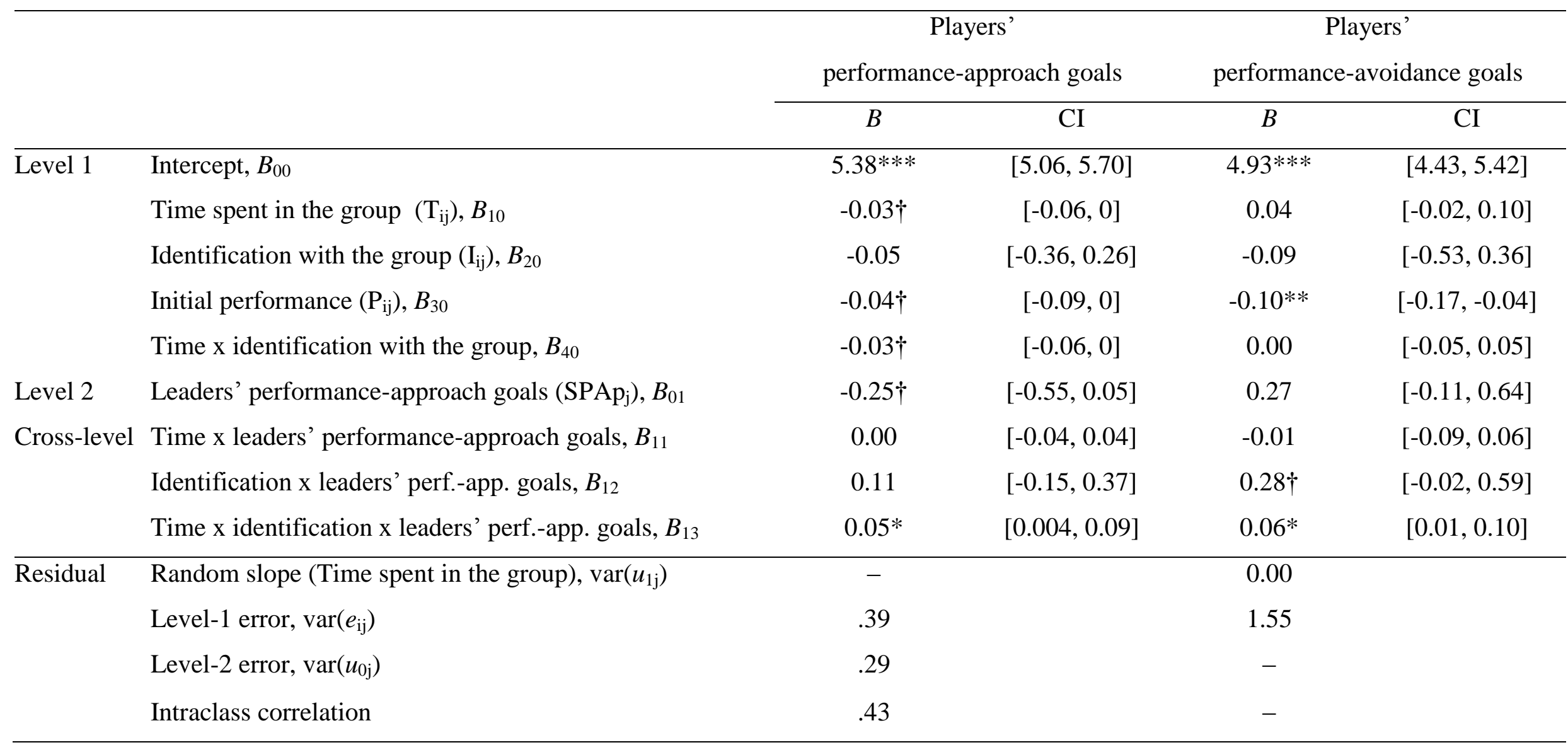

Note: The equation of the cross-level interaction model is $\mathrm{Y}_{\mathrm{ij}}=B_{00}+B_{10} * \mathrm{~T}_{\mathrm{ij}}+B_{20} * \mathrm{I}_{\mathrm{ij}}+B_{30} * \mathrm{P}_{\mathrm{ij}}+B_{40} * \mathrm{~T}_{\mathrm{ij}} * \mathrm{I}_{\mathrm{ij}}+B_{01} * \mathrm{SPAp}_{\mathrm{j}}+B_{11} * \mathrm{~T}_{\mathrm{ij}} *$ $\mathrm{SPAp}_{\mathrm{j}}+B_{12} * \mathrm{I}_{\mathrm{ji}} * \mathrm{SPAp}_{\mathrm{j}}+B_{13} * \mathrm{~T}_{\mathrm{ij}} * \mathrm{I}_{\mathrm{ji}} * \mathrm{SPAp}_{\mathrm{j}}+u_{1 \mathrm{j}} * \mathrm{~T}_{\mathrm{ij}}+u_{0 \mathrm{j}}+e_{\mathrm{ij}} ; * * *<.001, * * p<.01, * p<.05, \dagger p<.1$. 
Table 5.

Coefficient estimates and confidence intervals for the models testing the effects of teacher's performance-approach goal and pupils' perceived self-competence on pupils' performance goals (Study 4).

Level 1 Intercept, $B_{000}$

Perceptions of self-competence $\left(\mathrm{SC}_{\mathrm{ijk}}\right), B_{100}$

Players'

Players'

performance-approach goals performance-avoidance goals

Teacher familiarity $\left(\mathrm{F}_{\mathrm{ijk}}\right), B_{200}$

\begin{tabular}{cccc}
\hline$B$ & CI & $B$ & CI \\
\hline$-0.29 * * *$ & {$[-0.41,-0.17]$} & $-0.13^{*}$ & {$[-0.24,-0.02]$} \\
$-0.03 \dagger$ & {$[-0.05,0]$} & $-0.03^{*}$ & {$[-0.06,0.00]$} \\
$0.18^{* * *}$ & {$[0.14,0.23]$} & -0.04 & {$[-0.18,0.10]$} \\
-0.01 & {$[-0.05,0.03]$} & -0.03 & {$[-0.09,0.02]$} \\
- & - & $0.19 * * *$ & {$[0.15,0.24]$} \\
$0.02^{* *}$ & {$[0.01,0.04]$} & 0.01 & {$[-0.03,0.04]$} \\
- & - & 0.00 & {$[-0.01,0.02]$} \\
- & - & -0.05 & {$[-0.13,0.03]$} \\
- & - & $0.04 *$ & {$[0.01,0.07]$} \\
\hline
\end{tabular}

Level 2a Pupils' performance goals $\left(\mathrm{PG}_{\mathrm{j}}\right), B_{010}$

Level $2 \mathrm{~b}$ Teachers' performance-approach goals $\left(\mathrm{SPAp}_{\mathrm{k}}\right), B_{001}$

Cross-level Self-competence x teachers' goals, $B_{101}$

Familiarity x teachers' goals, $B_{102}$

Self-competence x familiarity x teachers' goals, $B_{103}$

Residual Random slope (Perceptions of self-competence), $\operatorname{var}\left(u_{1 \mathrm{jk}}\right)$

0.01

0.13

Random slope (Teachers' perf.-approach goals), $\operatorname{var}\left(u_{2 \mathrm{k}}\right)$

0.05

Level-1 error, $\operatorname{var}\left(e_{\mathrm{ijk}}\right)$

1.13

1.16

Level-2a error, $\operatorname{var}\left(u_{0 \mathrm{j}}\right)$

1.50

1.01

Level-2b error, $\operatorname{var}\left(u_{0 \mathrm{k}}\right)$

0.00

0.00

Level-2a intraclass correlation

Note: The equation of the cross-level interaction model is $\mathrm{Y}_{\mathrm{ijk}}=B_{000}+B_{100} * \mathrm{SC}_{\mathrm{ijk}}+B_{200} * \mathrm{~F}_{\mathrm{ijk}}+B_{300} * \mathrm{SC}_{\mathrm{ijk}} * \mathrm{~F}_{\mathrm{ijk}}+B_{010} * \mathrm{PG}_{\mathrm{j}}+B_{001} * \mathrm{SPAp}_{\mathrm{k}}+$ $B_{101} * \mathrm{SC}_{\mathrm{ijk}} * \mathrm{SPAp}_{\mathrm{k}}+B_{102} * \mathrm{~F}_{\mathrm{ijk}} * \mathrm{SPAp}_{\mathrm{k}}+B_{103} * \mathrm{SC}_{\mathrm{ijk}} * \mathrm{~F}_{\mathrm{ijk}} * \mathrm{SPAp}_{\mathrm{k}}+u_{1 \mathrm{jk}} * \mathrm{SC}_{\mathrm{ijk}}+u_{2 \mathrm{k}} * \mathrm{SPAp}_{\mathrm{k}}+u_{0 \mathrm{k}}+u_{0 \mathrm{j}}+e_{\mathrm{ijk}} ; * * p<.001, * * p<.01, * p$ $<.05, \dagger p<.1$. 


\section{Figure Captions}

Figure 1. Graphical representation of the socialization of performance goals (first panel from the top; Hypothesis 1a and 1b), consequences (second panel; Hypothesis 2a and 2b), enabling condition (third panel; Hypothesis $3 \mathrm{a}$ and $3 \mathrm{~b}$ ), and directional moderator (fourth panel; Hypothesis 4a and 4b). PAp stands for performance-approach and PAv for performance-avoidance.

Figure 2. Players' performance-approach (left panel) and -avoidance (right panel) goals as a function of coaches' performance-approach goals and number of years players spent under the supervision of the coach. Study 1.

Figure 3. Moderation effect of thesis supervisors' performance-approach and time Ph.D. spent under their supervision on Ph.D. students' intention to drop out and satisfaction, through Ph.D. students' performance-approach and -avoidance goals. Study 2. Note. ${ }^{*} p<.05, * * p<.01$.

Figure 4. Ph.D. students' intention to drop out from thesis (left panel) and satisfaction (right panel) as a function of thesis supervisors' performance-approach goals and number of years Ph.D. students spent under the supervision of the supervisor. Study 2.

Figure 5. Team-members' performance-approach (left panel) and -avoidance (right panel) goals as a function of team-members' identification with their team when time spent under the supervision of the coach is high (+1 SD). Study 3 .

Figure 6. Pupils' change in performance-approach (left panel) and -avoidance (right panel) goals as a function of teachers' performance-approach goals and pupils' perception of self-competence. For the right panel, the interaction concerns the case where teacher was unknown before school year began. Study 4. 

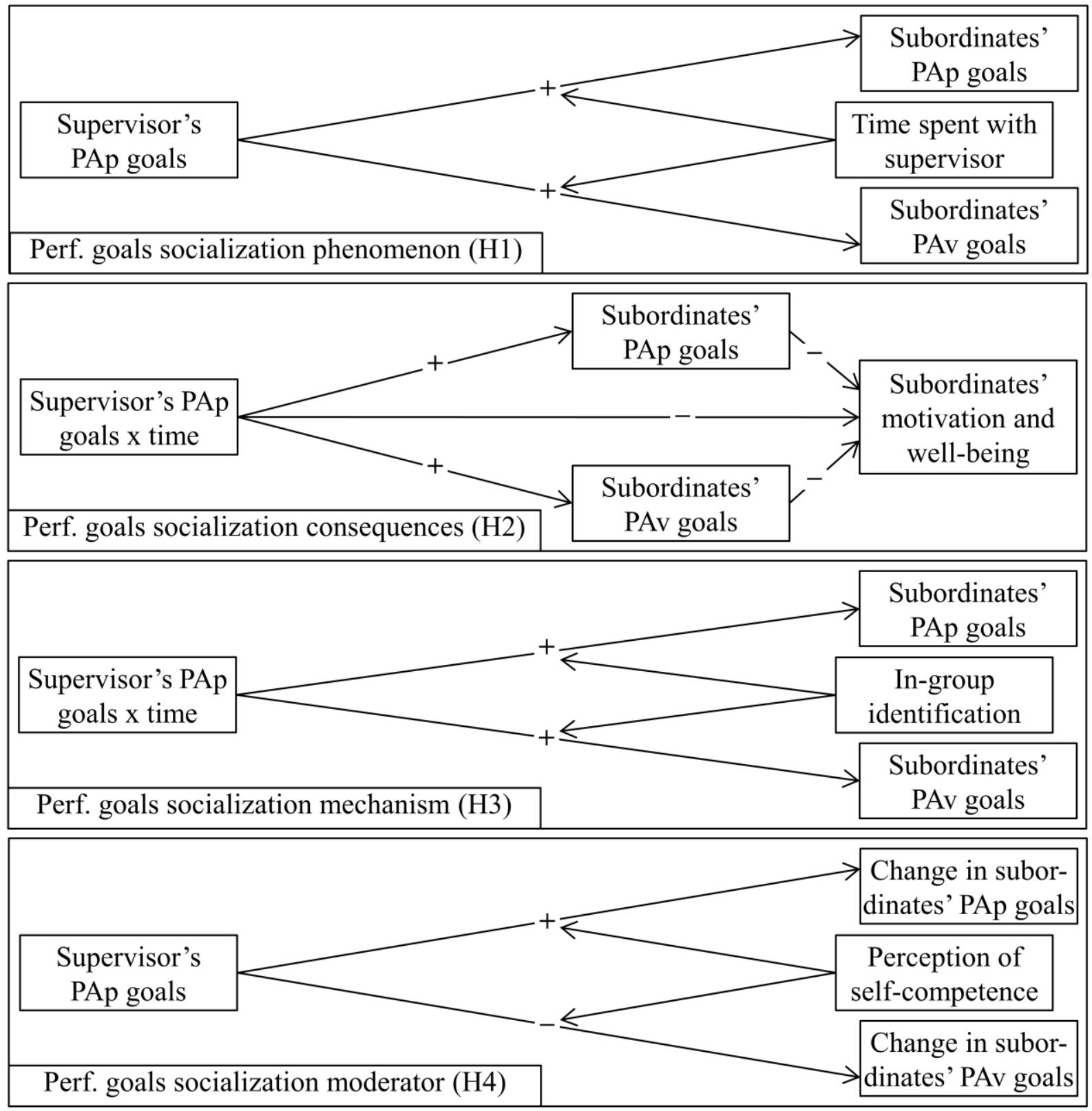

Figure 1. 

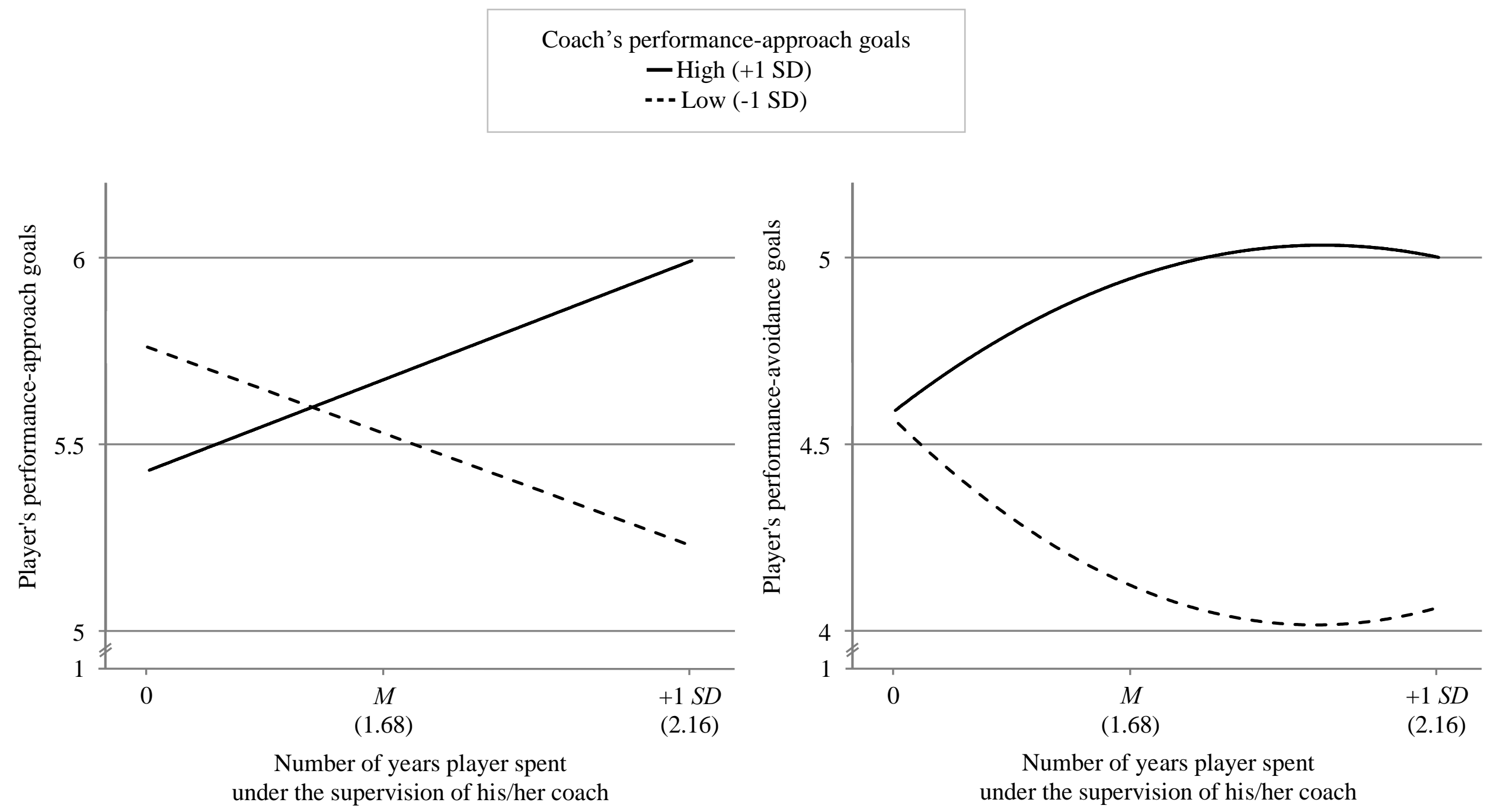

Figure 2. 
PERFORMANCE GOALS SOCIALISATION

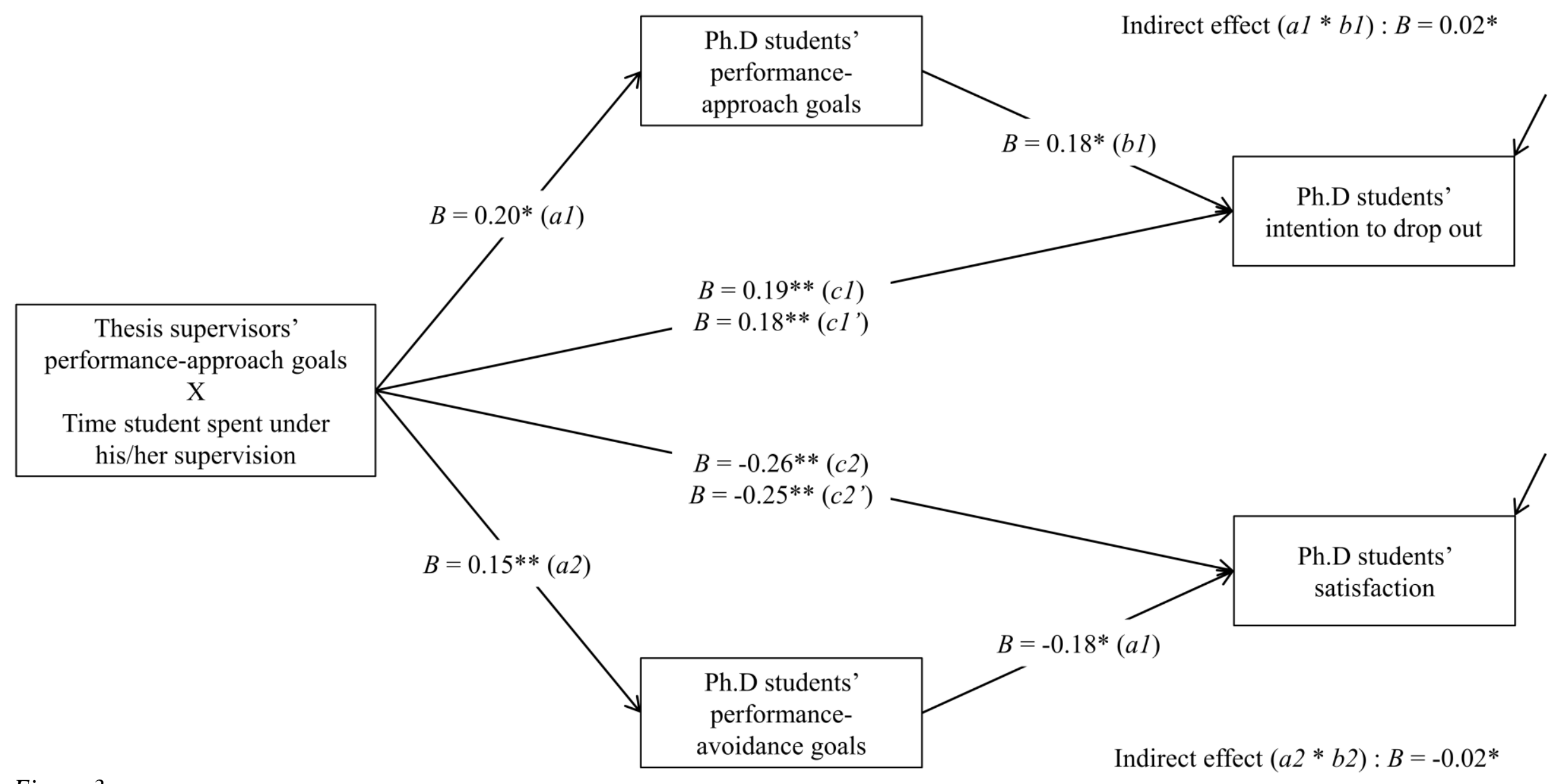

Figure 3. 
Supervisor's performance-approach goals

$$
\text { - High (+1 SD) }
$$

-- - Low (-1 SD)

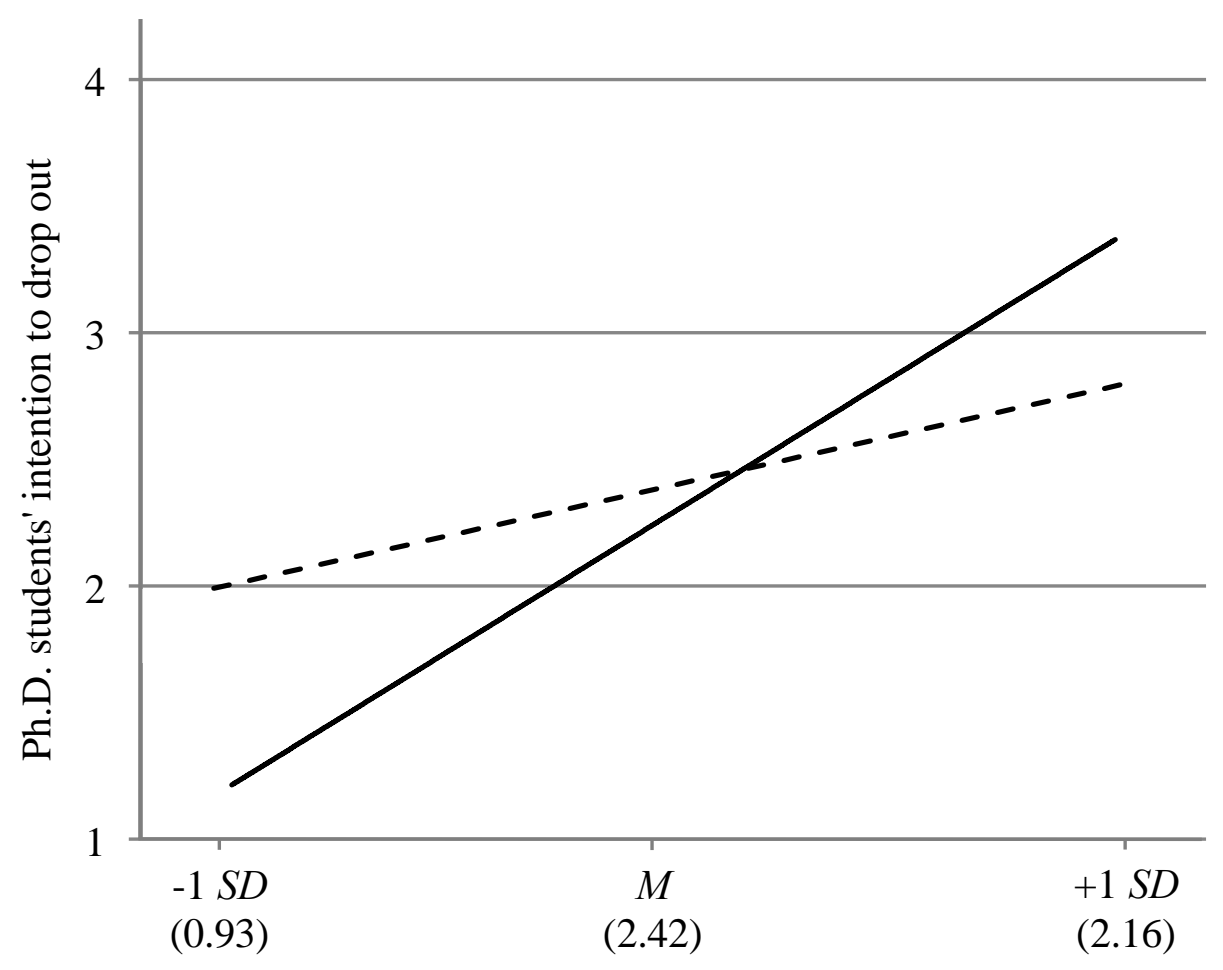

Number of years Ph.D. student spent under the supervision of his/her thesis supervisor

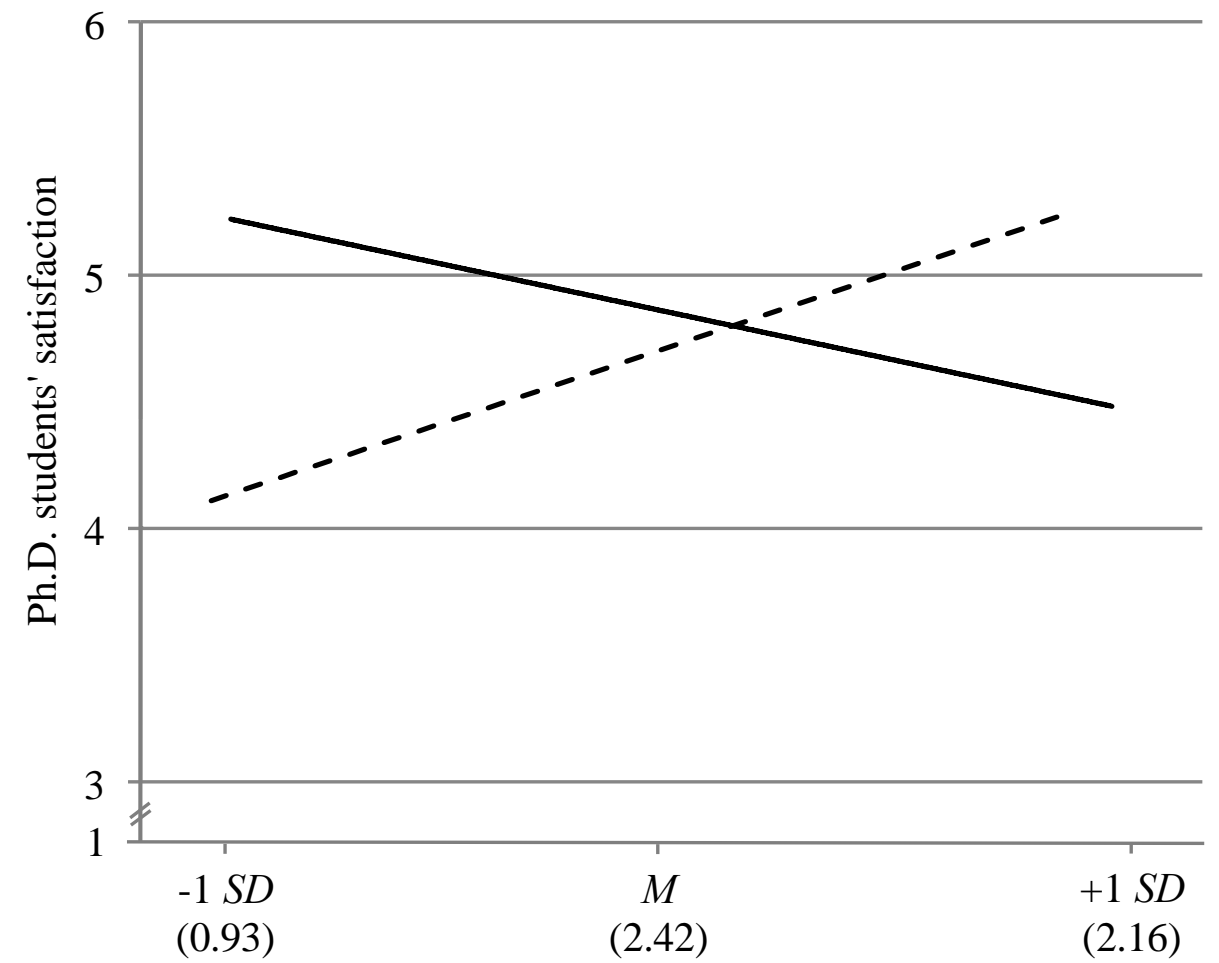

Number of years Ph.D. student spent under the supervision of his/her thesis supervisor

Figure 4. 

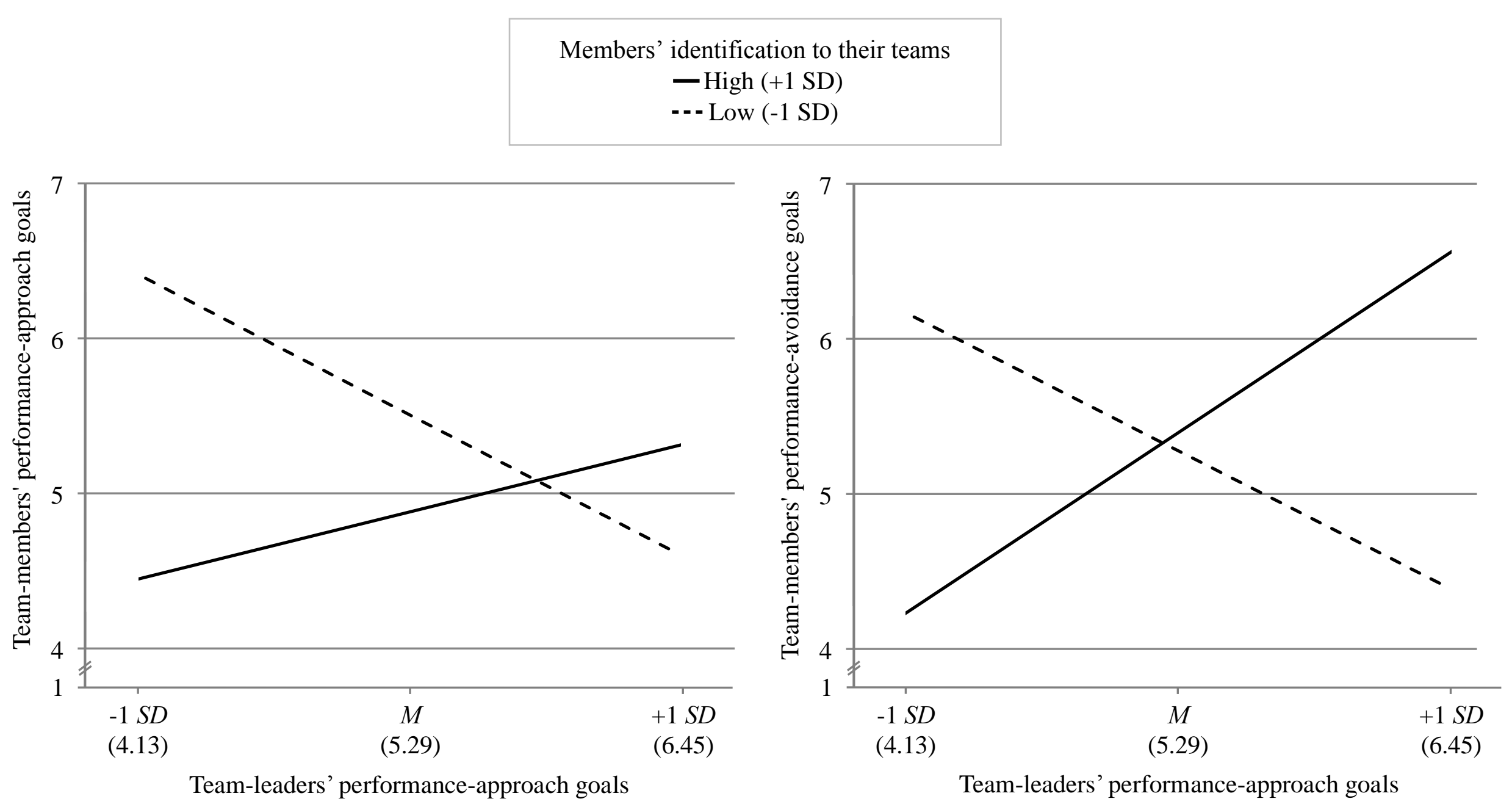

Figure 5. 
PERFORMANCE GOALS SOCIALISATION
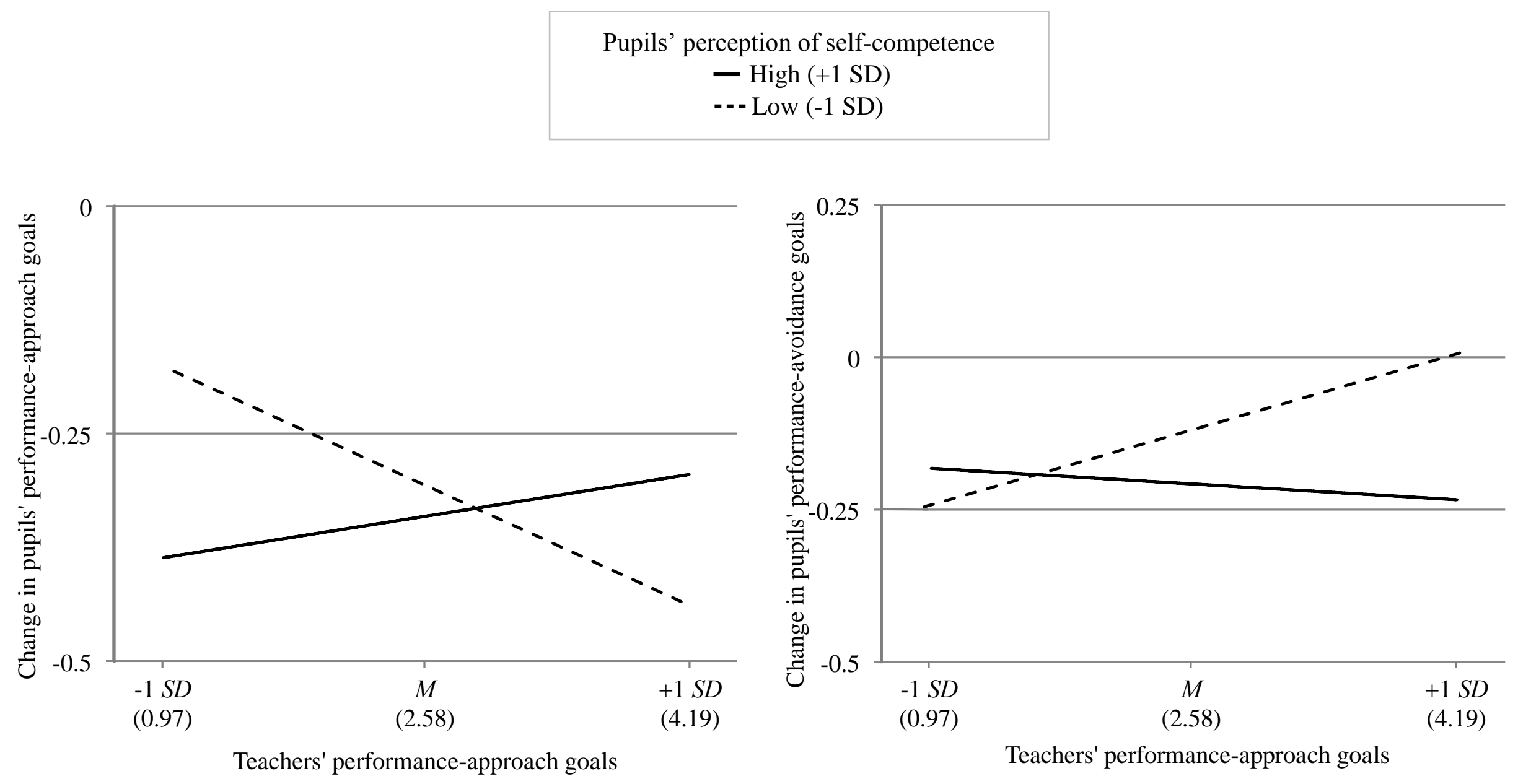

Figure 6. 